OPEN ACCESS

Check for updates

\section{Perioperative interventions for prevention of postoperative pulmonary complications: systematic review and meta-analysis}

\author{
Peter M Odor, ${ }^{1}$ Sohail Bampoe, ${ }^{1}$ David Gilhooly, ${ }^{1}$ Benedict Creagh-Brown, ${ }^{2,3}$ \\ S Ramani Moonesinghe ${ }^{1,4}$
}

${ }^{1}$ Department of Anaesthesia and Perioperative Medicine, University College Hospital, London, UK

${ }^{2}$ Surrey Perioperative Anaesthesia Critical care collaborative Research (SPACeR) Group, Intensive Care Unit, Royal Surrey County Hospital NHS Foundation Trust, Guildford, UK Experimental Medicine, Faculty of Health and Medical Sciences, University of Surrey, Guildford, UK

${ }^{4}$ UCL/UCLH Surgical Outcomes Research Centre, UCL Centre for Perioperative Medicine, Research Department for

Targeted Intervention, Division of Surgery and Interventional

Science, University College

London, London, UK peter.odor@nhs.net

(or @ peteodor on Twitter:

orcid 0000-0003-4642-2703))

Additional material is published online only. To view please visit the journal online.

Cite this as: $B M J$ 2020;368:m540 http://dx.doi.org/10.1136/bmj.m540

Accepted: 20 January 2020
${ }^{3}$ Department of Clinical and

Correspondence to: PM Odor

\section{ABSTRACT}

OBJECTIVE

To identify, appraise, and synthesise the best available evidence on the efficacy of perioperative interventions to reduce postoperative pulmonary complications (PPCs) in adult patients undergoing non-cardiac surgery.

\section{DESIGN}

Systematic review and meta-analysis of randomised controlled trials.

\section{DATA SOURCES}

Medline, Embase, CINHAL, and CENTRAL from January 1990 to December 2017.

ELIGIBILITY CRITERIA

Randomised controlled trials investigating short term, protocolised medical interventions conducted before, during, or after non-cardiac surgery were included. Trials with clinical diagnostic criteria for PPC outcomes were included. Studies of surgical technique or physiological or biochemical outcomes were excluded.

\section{DATA EXTRACTION AND SYNTHESIS}

Reviewers independently identified studies, extracted data, and assessed the quality of evidence. Metaanalyses were conducted to calculate risk ratios with 95\% confidence intervals. Quality of evidence was summarised in accordance with GRADE methods. The primary outcome was the incidence of PPCS. Secondary outcomes were respiratory infection, atelectasis, length of hospital stay, and mortality. Trial sequential analysis was used to investigate the reliability and conclusiveness of available evidence. Adverse effects of interventions were not measured or compared.

\section{WHAT IS ALREADY KNOWN ON THIS TOPIC}

Postoperative pulmonary complications (PPCs) are common and have an important effect on morbidity and mortality after surgery, with associated resource use and cost implications

Various interventions are available that aim to reduce the risk of PPCs

Evidence shows a mismatch between routine clinical practice to prevent PPCs and outcome data from trials of interventions

\section{WHAT THIS STUDY ADDS}

This study provides an overview of the efficacy of different interventions to reduce development of PPCs

No high quality evidence supported the efficacy of any interventions, but moderate quality evidence showed that intraoperative lung protective ventilation and goal directed haemodynamic strategies reduce PPCS

Moderate quality evidence does not support incentive spirometry therapy, and only low quality evidence was available for other treatment interventions

\section{RESULTS}

117 trials enrolled 21940 participants, investigating 11 categories of intervention. 95 randomised controlled trials enrolling 18062 participants were included in meta-analysis; 22 trials were excluded from meta-analysis because the interventions were not sufficiently similar to be pooled. No high quality evidence was found for interventions to reduce the primary outcome (incidence of PPCs). Seven interventions had low or moderate quality evidence with confidence intervals indicating a probable reduction in PPCs: enhanced recovery pathways (risk ratio $0.35,95 \%$ confidence interval 0.21 to $0.58)$, prophylactic mucolytics $(0.40,0.23$ to 0.67$)$, postoperative continuous positive airway pressure ventilation $(0.49,0.24$ to 0.99$)$, lung protective intraoperative ventilation $(0.52,0.30$ to 0.88$)$, prophylactic respiratory physiotherapy $(0.55,0.32$ to 0.93$)$, epidural analgesia $(0.77,0.65$ to 0.92$)$, and goal directed haemodynamic therapy $(0.87$, 0.77 to 0.98 ). Moderate quality evidence showed no benefit for incentive spirometry in preventing PPCs. Trial sequential analysis adjustment confidently supported a relative risk reduction of $25 \%$ in PPCs for prophylactic respiratory physiotherapy, epidural analgesia, enhanced recovery pathways, and goal directed haemodynamic therapies. Insufficient data were available to support or refute equivalent relative risk reductions for other interventions.

\section{CONCLUSIONS}

Predominantly low quality evidence favours multiple perioperative PPC reduction strategies. Clinicians may choose to reassess their perioperative care pathways, but the results indicate that new trials with a low risk of bias are needed to obtain conclusive evidence of efficacy for many of these interventions.

\section{STUDY REGISTRATION}

Prospero CRD42016035662.

\section{Introduction}

Despite advances in perioperative care for patients undergoing major surgery, postoperative pulmonary complications (PPCs) represent a leading cause of morbidity and mortality. The term PPC encompasses a range of conditions affecting the respiratory system, typically within the first week after surgery. Examples range from atelectasis to respiratory failure. ${ }^{12}$

PPCs are among the most common post-surgical complications, ${ }^{3-7}$ with a prevalence between $1 \%$ and $23 \%$, varying considerably depending on patient related and surgical factors. For example, ankle surgery in a healthy, young person may have risk of PPCs of less than $1 \%$ and upper gastrointestinal 
surgery in a frail, older patient will have a much higher risk. Proximity of surgical incision to the thorax, where pain disrupts the performance of respiratory muscles after surgery, is a strong predictor of PPCs, as is age, with even healthy older patients being at higher risk of PPCs. ${ }^{8}$ PPCs are also predictors of short term and long term health outcomes after surgery and are associated with increased risk of admission to critical care and prolonged length of hospital stay. ${ }^{910}$ Between $14 \%$ and $30 \%$ of patients developing a PPC will die within 30 days of major surgery, compared with $0.2-3 \%$ of those without a PPC. ${ }^{9}$

The causes of PPCs are multifactorial and relate to both the patient's chronic health and the acute adverse effects of surgery with accompanying anaesthesia. ${ }^{11}$ Surgery itself can depress lung function, particularly when surgical pain impairs breathing. Anaesthesia adversely affects lung function intraoperatively, and, to a lesser extent, these effects persist into the postoperative period. Well established chronic risk factors for PPC include poor cardiorespiratory health, increased age, lifestyle factors, and habitus. ${ }^{12}$

Fortunately, multiple opportunities exist to intervene and therefore potentially prevent the development of PPCs. Interventions are diverse, covering pre-emptive strategies (before surgery) to optimise respiratory physiology and intraoperative and postoperative interventions to minimise the adverse effects of surgery and anaesthesia. Table 1 shows examples of interventions used in clinical practice in resourced healthcare systems.

Treatment of PPCs requires multidisciplinary involvement across anaesthesia, surgery, respiratory medicine, physiotherapy, and critical care specialties, with associated economic and health outcome burden. ${ }^{13}$ Despite this, consensus guidelines for perioperative management aimed at reducing the risk of PPCs are infrequent or outdated compared with those for cardiovascular complications following surgery. ${ }^{1415}$ This lack of consensus, arising from a broad and diverse evidence base across many interventions, results in much variation in clinical practice.

The aim of this systematic review was to summarise the evidence from randomised controlled trials (RCTs) of perioperative interventions designed to reduce PPCs in adults after non-cardiac surgery. RCTs designed to reduce the incidence of PPC generally consider noncardiac surgery separately from cardiac surgery. We chose to focus exclusively on non-cardiac surgery because it is more common. We aimed to compare quality, quantity, and risk of bias for evidence of treatment effects for PPC management. Inherent to this approach is a focus on whether benefits are associated with each treatment, rather than comparing their adverse effects. This is because although the benefits of treatments should be similar, the harms vary substantially because the interventions work in very different ways and they may not share common harms. The principal purpose of the review is to inform clinicians wishing to improve their evidence based perioperative care pathways and, by highlighting deficiencies in our evidence base, to facilitate researchers and funders in focusing on areas of greatest need.

\section{Methods \\ Protocol}

Our methods and reporting conform to the Preferred Reporting Items for Systematic Reviews and MetaAnalyses (PRISMA) and Cochrane guidelines. ${ }^{16} 17$ This study is registered with the International Prospective Register of Systematic Reviews, number CRD42016035662. The registration includes a prespecified protocol, which was amended to include length of hospital stay as a replacement secondary outcome measure, alongside a revised categorisation system for types of intervention. We adjusted the search strategy to include an earlier start date for included studies and further secondary search strategies for interventions of relevance. We added trial sequential analysis to the statistical methods. We did not consider network meta-analysis to be suitable, as the studies lack homogeneity in terms of the participants and the definitions of control and intervention.

\section{Search strategy}

We searched Medline, Embase, CINHAL, and the Cochrane Central Register of Controlled Trials, using

\begin{tabular}{|c|c|c|c|c|}
\hline What is it? & Is it used commonly? & $\begin{array}{l}\text { How burdensome for } \\
\text { patients? }\end{array}$ & How tricky for providers? & Cost \\
\hline Enhanced recovery pathways & Increasingly commonly used & Minimal & Simple (once established) & Neutral \\
\hline Prophylactic mucolytics & Not commonly used & Minimal & Simple & $f$ \\
\hline $\begin{array}{l}\text { Postoperative ventilatory support } \\
\text { (CPAP, NIV, or HFNC) }\end{array}$ & Not commonly used* & Moderate & Complex & $f f$ \\
\hline Lung protective ventilation intraoperatively & Not commonly used & None & Simple & Neutral \\
\hline Respiratory physiotherapy & Not commonly used* & Mild & Complex & $f f$ \\
\hline Epidural analgesia & Commonly used & Mild & Moderate & $f f$ \\
\hline Goal directed fluid therapy & Variably used internationally & None & Moderate & $f f$ \\
\hline Incentive spirometry & Variably used internationally & Mild & Simple & $f$ \\
\hline Inhaled therapies (in addition to usual drugs) & Not commonly used* & Mild & Simple & $f$ \\
\hline Smoking cessation & Commonly recommended & Moderate & Simple & Neutral \\
\hline
\end{tabular}


a combination of relevant keywords and medical subject heading terms for postoperative pulmonary complications. Search limits were applied to restrict results to RCTs published from 1 January 1990 to 8 December 2017. We chose the start date to overlap with the last systematic review into strategies for prevention of PPCs, ${ }^{14}$ as well as to restrict trials to contemporary surgical and anaesthesia practice, including laparoscopic surgery techniques. Subject headings and text terms for intraoperative complications, postoperative complications, perioperative complications, preoperative care, intraoperative care, perioperative care, postoperative care, or anaesthesia were combined with descriptive terms relevant to postoperative respiratory complications based on European Perioperative Clinical Outcome (EPCO) definitions (table 2). ${ }^{1}$ Full search terms and search strategy are provided in appendix 1 . Secondary searching included manual searching of relevant reference lists for articles not identified in the primary search and review of citation listings in Web of Science. In addition, we did focused searches for perioperative fluid administration and haemodynamic management strategies, intraoperative neuromuscular blockade and monitoring, and airway device and supraglottic suctioning techniques.

\section{Study selection \\ Population}

We included RCTs of adult (age $\geq 18$ years) patients undergoing non-cardiac surgery, excluding organ transplantation surgery (as findings in patients who need immunosuppression may not be generalisable to others).

\section{Intervention}

We considered all perioperative care interventions identified by the search if they were protocolised (therapies were systematically provided to patients according to pre-defined algorithm or plan) and were started and completed during the perioperative pathway (that is, during preoperative preparation for surgery, intraoperative care, or inpatient postoperative recovery). Examples of interventions that we did or did not deem perioperative in nature included long term preoperative drug treatment (not included, as not started and completed during the perioperative pathway) and perioperative physiotherapy interventions (included, as both started and completed during the perioperative pathway). We excluded studies in which the intervention was directly related to surgical technique.

\section{Outcomes}

To be included, a trial had to use a defined clinical outcome relating to PPC, such as "pneumonia" diagnosed according to the Centers for Disease Control and Prevention's definition. RCTs reporting solely physiological (for example, lung volumes and flow measurements) or biochemical (for example, lung inflammatory markers) outcomes are valuable but neither patient centric nor necessarily clinically relevant, and we therefore excluded them. We applied no language restrictions.

Our primary outcome measure was the incidence of PPCs, with PPCs being defined as the composite of any of respiratory infection, respiratory failure, pleural effusion, atelectasis, or pneumothorax. As the search period pre-dated the most recent consensus definitions of PPC, ${ }^{118}$ we categorised explicit descriptions of PPCs in each trial according to closeness of match to the EPCO definitions. ${ }^{1}$ Where a composite PPC was not reported, we contacted corresponding authors via email to request additional information, including primary data. Secondary outcomes were the incidence of subtypes of PPC (including respiratory infection, respiratory failure, pleural effusion, atelectasis, and pneumothorax), length of hospital stay, and in-hospital mortality. However, our analysis incorporated only the three most commonly reported secondary pulmonary outcome measures.

\section{Data abstraction and risk of bias assessment}

Two of three reviewers used pre-piloted abstraction forms to independently extract study characteristics and outcomes for each trial. Risk of bias was assessed using the Cochrane Collaboration tool. ${ }^{19}$ Disagreements were resolved by consensus or by consultation with a third reviewer. Where necessary, we contacted authors of relevant studies to obtain additional information. For studies published more than once (duplicates), we included only the report with the most informative and complete data.

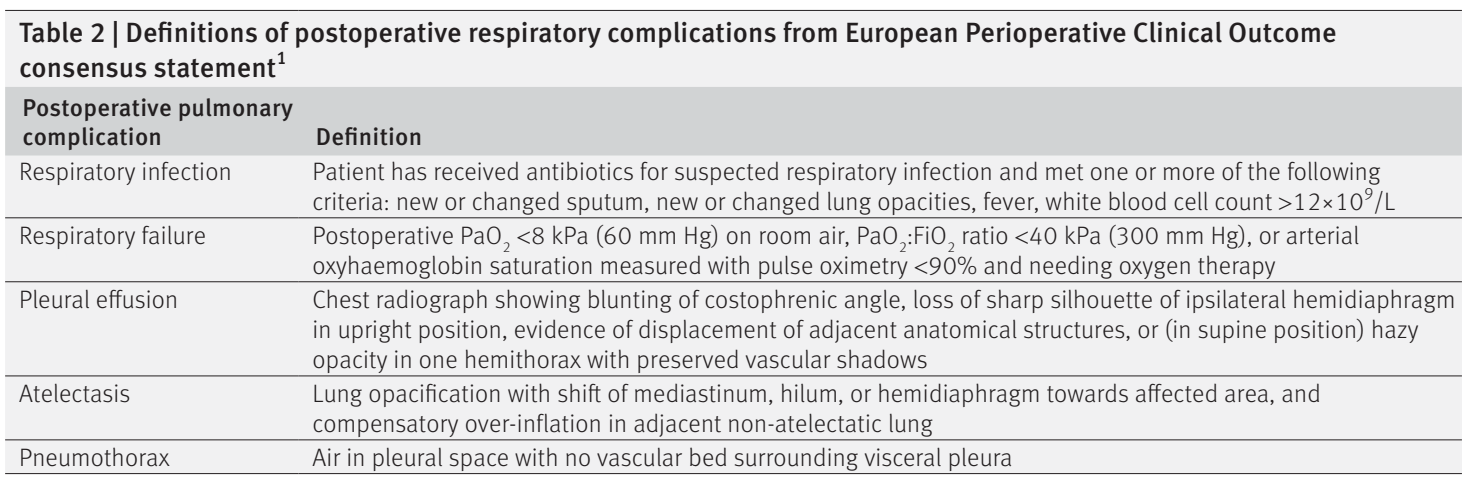


Data synthesis and statistical methods

For dichotomous data, including binary PPC outcomes, we used risk ratios as the effect measure with 95\% confidence intervals calculated using the Mantel-Haenszel method. For continuous data, we presented the results as mean differences with 95\% confidence intervals calculated using an inverse variance method. We converted results for length of hospital stay from median and range and/or interquartile range to mean and standard deviation. ${ }^{2021}$ When studies included two or more intervention groups, we merged data into a single group only if the interventions were sufficiently similar. We did meta-analysis when it was reasonable to assume that studies were estimating the same underlying treatment effect on PPC outcomes and two or more studies could be included with measures of clinical, methodological, and statistical heterogeneity indicating that pooling of results was appropriate. We assessed for statistical heterogeneity between studies by using the $\mathrm{I}^{2}$ statistic. When producing an overall summary estimate, we used random effects models in meta-analysis, as sufficient clinical heterogeneity existed for us to expect that the underlying treatment effects would differ between trials. ${ }^{22}{ }^{23}$ We generated summary forest plots for each intervention by using individual meta-analysis data weighted according to the inverse variance method.

Werated thequality of evidencefor eachintervention according to the Grades of Recommendation, Assessment, Development, and Evaluation (GRADE) Working Group system. ${ }^{24}$ Conventional meta-analyses may result in type I errors due to random error from studies with low quality, a small sample size, or publication bias. Likewise, results from smaller trials are often overruled when results from adequately powered larger trials emerge. We used trial sequential analysis for included studies in the meta-analysis to estimate and correct these limitations and determine whether the cumulative evidence was appropriately powered. ${ }^{23} 25$ Trial sequential analysis can also guide conduct of new high quality trials or prevent unnecessary trials if intervention effects are found to be large and the required information size has been reached. A network meta-analysis was not suitable owing to trial heterogeneity.

Our assumptions included an a priori determined intervention effect of a $25 \%$ risk ratio reduction in PPCs, two sided testing with a type I error of $5 \%$, and a type II error of $20 \%$ (power of $80 \%$ ). We constructed both conventional (with $\alpha$ of $5 \%$ ) and trial sequential monitoring boundaries for intervention and control group comparisons. The heterogeneity correction in the trial sequential analysis was set to variance based, and the random effects model was applied. We constructed a cumulative, sequential z score curve and used it to evaluate the adequacy of the evidence. We calculated the diversity adjusted required information size, or the number of participants needed in a metaanalysis to detect or reject a certain intervention effect, by using the above modelling. We used Trial
Sequential Analysis software 0.9. ${ }^{26}$ We compiled a narrative review of trial results and characteristics where trials where unsuitable for meta-analysis.

\section{Patient and public involvement}

Patients were not involved in setting this specific research question or the outcome measures. However, our research group is incorporating patient and lay perspectives into future work following this review, including the development of care bundle proposals to reduce PPCs. More specifically, we are considering patient feedback on how prophylactic interventions can be delivered sensitively and comfortably at a time when patients may feel pain, stressed, or fatigued around the time of surgery. For this paper we are expanding our dissemination by writing a BMJ perspective article about our research.

\section{Results}

\section{Description of included studies}

The literature search retrieved 4525 unique citations. Of these, 117 parallel group RCTs, including 21940 adult patients, conducted between 1990 to 2017 in 27 countries fulfilled the inclusion criteria (fig 1). Twenty one RCTs were ineligible for meta-analysis, either because the interventions were not sufficiently similar to be pooled with other RCTs or because they were investigating an intervention evaluated in a single trial only. One trial was withheld from metaanalysis because it did not include a standard care control group. The meta-analysis therefore included 95 RCTs, incorporating data from 18062 participants. Study characteristics, risk of bias assessment, outcomes, and references of all 117 trials are shown in appendix 2. Subgroup analysis according to type of surgery is provided in appendix 3. The total proportion of patients who were diagnosed as having PPCs in the included RCTs (in both control and intervention groups) was 3164/21940 (14.4\%).

All patients received general anaesthesia, with or without a neuraxial block or regional anaesthetic adjunct, except for one trial in the narrative evaluation that compared patients with hip fracture receiving spinal or general anaesthesia. Most patients included in trials underwent laparotomy or open surgical techniques (table 3). The primary outcome measure of PPC was reported or derived for all studies. Reporting of secondary PPC subtypes varied (table 4). We identified 34 different strategies for reducing the risk of PPCs, which we grouped into 11 categories based on mode of intervention (table 5). Analysis of funnel plots showed no obvious evidence of publication bias or that results of smaller trials were systematically different from those of larger trials (appendix 2). We judged most of the studies to have at least some concerns about risk of bias according to the Cochrane instrument (fig 2).

\section{Principal findings}

We identified seven perioperative interventions with confidence intervals from conventional meta-analysis 


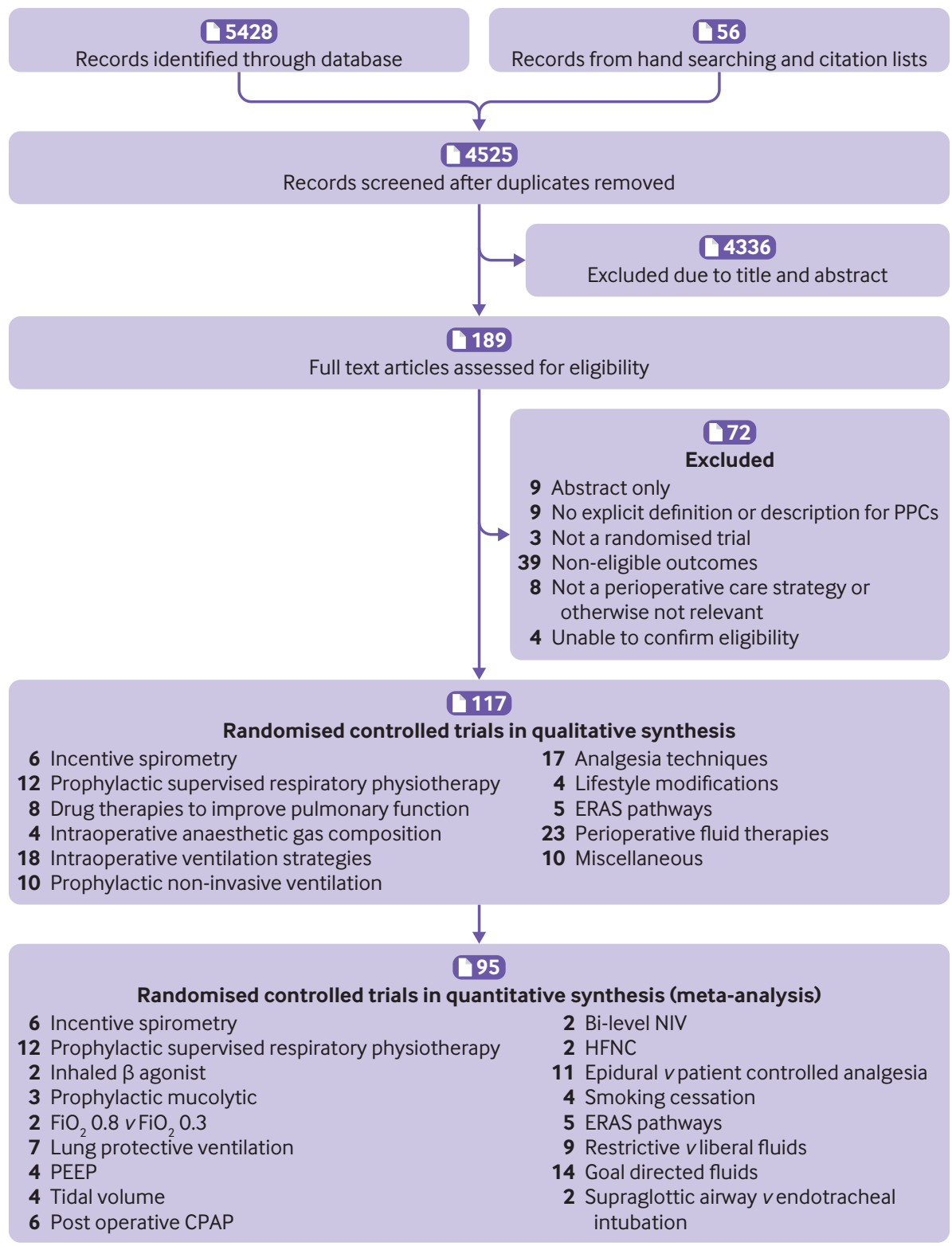

Fig 1 | Screening and selection of studies for systematic review and meta-analysis of postoperative pulmonary complication (PPC) outcomes. CPAP=continuous positive airway pressure; $E R A S=$ enhanced recovery after surgery; $\mathrm{FiO}_{2}=$ fractional inspiration oxygen; $\mathrm{HFNC}=$ high flow nasal cannula; $\mathrm{NIV=non-invasive} \mathrm{ventilation;} \mathrm{PEEP}=$ positive end expiratory pressure

indicating a probable reduction in PPCs: use of enhanced recovery after surgery pathways, prophylactic mucolytics, postoperative continuous positive airway pressure non-invasive ventilation, lung protective intraoperative ventilation, prophylactic respiratory physiotherapy, epidural analgesia, and goal directed haemodynamic therapy (summarised in table 6). A further seveninterventions did not meet statisticallimits (all $\mathrm{P}>0.05$ ) for treatment benefit: restrictive versus liberal fluid administration strategies, postoperative bi-level non-invasive ventilation, postoperative high flow nasal cannula oxygenation, smoking cessation therapy, inhaled $\beta$ agonists, incentive spirometry, and variation in intraoperative fractional inspiration oxygen concentration (fig 3). Confidence intervals for risk ratios derived from conventional meta-analysis indicate wide imprecision for most estimates of the treatment effects of interventions. Only marginal differences for continuous positive airway pressure, for example, separate the statistical finding for this intervention as beneficial (at $\mathrm{P}=0.05$ ).

We used trial sequential analysis to evaluate the robustness of our meta-analysis (table 7). Firm evidence of a $25 \%$ relative risk reduction is defined by a cumulative $\mathrm{z}$ curve crossing the calculated trial sequential monitoring boundary before the calculated diversity adjusted required information size is reached. Alternatively, firm evidence is also reached if the conventional $\mathrm{z}=-1.96$ or $\mathrm{z}=1.96$ monitoring boundary is crossed and the actual information size exceeds the diversity adjusted required information size. If the cumulative $\mathrm{z}$ curve crosses the conventional boundary 


\begin{tabular}{|c|c|}
\hline \multicolumn{2}{|c|}{$\begin{array}{l}\text { Table } 3 \text { | Selected trial characteristics, including largest proportion of surgical type } \\
\text { received by recruited patients in each trial. Values are numbers (percentages) }\end{array}$} \\
\hline Characteristic & $\begin{array}{l}\text { Randomised controlled } \\
\text { trials }(n=112)\end{array}$ \\
\hline Only patients aged $\geq 65$ years & $4(4)$ \\
\hline$>200$ participants & $23(21)$ \\
\hline Baseline ARISCAT score $\geq 26$ (intermediate or high predictive risk of PPC) & $8(7)$ \\
\hline \multicolumn{2}{|l|}{ Type of surgery } \\
\hline Laparoscopic surgical technique & $9(8)$ \\
\hline Laparotomy or otherwise open surgical technique & $96(86)$ \\
\hline Lower abdominal surgery (eg, colonic resection) & $51(46)$ \\
\hline Upper abdominal surgery (eg, oesophagectomy, sleeve gastrectomy) & $16(14)$ \\
\hline Vascular surgery (eg, abdominal aortic aneurysm repair) & $12(11)$ \\
\hline Thoracic surgery (eg, lobectomy, video assisted thoracoscopy) & $24(21)$ \\
\hline Orthopaedic surgery (eg, spinal surgery, hip fracture repair) & $7(6)$ \\
\hline Maxillofacial surgery (major head and neck surgery with tracheostomy) & $1(1)$ \\
\hline Urological surgery (eg, robotic assisted radical prostatectomy) & $1(1)$ \\
\hline Obstetric surgery (eg, caesarean section) & $1(1)$ \\
\hline Neurosurgery (any neurosurgical procedure) & $1(1)$ \\
\hline
\end{tabular}

$\mathrm{PPC}=$ postoperative pulmonary complication.

but not the trial sequential monitoring boundary, the result may represent random error as a result of repetitive testing on accumulating data (nominal type I error). Trial sequential analysis results are available in full in appendix 4.

Only four of the seven interventions with evidence of benefit in conventional meta-analysis also showed firm evidence of benefit in trial sequential analysis: prophylactic respiratory physiotherapy, epidural analgesia, enhanced recovery after surgery, and goal directed haemodynamic therapies. However, all trials of these interventions were of only low to moderate quality. Despite firm evidence at trial sequential analysis, further randomised trials of these interventions may still be needed to reflect the changing nature of surgical practice and patients' characteristics. The remaining meta-analyses do not provide sufficient data for us to draw definitive conclusions on treatment effects when adjusted for sequential testing on an accumulating number of participants; hence, larger trials of these interventions are still required.

\section{Secondary outcomes}

Meta-analysis of respiratory infection and atelectasis outcomes were based on fewer data (fig 4 and fig 5) but indicated treatment effects for postoperative continuous positive airway pressure, mucolytics, respiratory physiotherapy, and enhanced recovery after surgery for both outcomes. Lung protective ventilation reduced the risk of atelectasis and respiratory infection, with similar confidence intervals and point estimates of treatment effects, but significance limits

\begin{tabular}{ll}
\hline \multicolumn{2}{l}{ Table $\mathbf{4}$ | Numbers (percentages) of randomised controlled trials (RCTs) reporting } \\
\begin{tabular}{ll} 
individual postoperative pulmonary complication subtypes as discrete outcomes \\
Type of postoperative pulmonary complication & Reported as discrete outcome in RCTs (n=112) \\
Respiratory infection & $79(71)$ \\
\hline Respiratory failure & $35(31)$ \\
\hline Pleural effusion & $7(6)$ \\
\hline Atelectasis & $37(33)$ \\
\hline Pneumothorax & $7(6)$ \\
\hline
\end{tabular}
\end{tabular}

were reached for atelectasis outcomes only. Only RCTs of enhanced recovery after surgery and goal directed haemodynamic therapy showed any reduction in length of hospital stay (fig 6), whereas very limited data suggested no benefits on in-hospital mortality for any intervention (fig 7). Although we found evidence of equivalent outcomes for PPCs with incentive spirometry, the point estimate and confidence interval for developing respiratory infections was large and weighted in favour of control groups, albeit on the basis of two trials only.

\section{Interventions with low to moderate supporting evidence of benefit}

We found no high quality evidence for any perioperative interventions in the reduction of PPC risk. Only low or moderate quality evidence was available.

\section{Enhanced recovery after surgery pathways}

Enhanced recovery pathways involve protocolised implementation of evidence based perioperative care. All studies were at high risk of bias. As a result, the quality of evidence was downgraded to low.

A total of five RCTs with a pooled total of 519 participants included enhanced recovery after surgery style care pathways and included PPCs as an outcome measure. ${ }^{27-31}$ None of the studies reported adequately on protocol compliance or prevention of cross contamination of control group patients enrolled at the same sites with intervention care. These confounders may have led to over-estimation or under-estimation of the effect size of enhanced recovery pathways on PPCs. Although we identified no obvious evidence of publication bias, the estimated treatment effect size was disproportionately large (risk ratio $0.35,95 \%$ confidence interval 0.21 to 0.58 ), especially given that the enhanced recovery protocols generally lacked pulmonary specific treatment components. Content of the enhanced recovery pathways varied from trial to trial, but all patients received a combination of at least three of the following elements: early ambulation, early feeding, protocolised analgesia, early removal of nasogastric tubes, and urinary catheters.

One study included thoracic surgical patients, ${ }^{32}$ three included abdominal gastrointestinal tract surgery patients, , $^{3031}$ and one included older patients with fractured neck of femur. ${ }^{29}$ Only one trial included patients receiving laparoscopic abdominal surgery $^{27}$; all other procedures were open, despite the laparoscopic surgical approach being a common feature of enhanced recovery pathways. Protocol compliance was not well reported, and the variability in the application of the principles of enhanced recovery after surgery between trials makes assessing effectiveness difficult. The trial of patients with hip fracture involved randomisation to rapid, expedited medical assessment and corrective surgery, but mobilisation and postoperative care were the same for both groups. ${ }^{29}$ This trial was excluded from metaanalysis for methodological heterogeneity. Full details 


\begin{tabular}{|c|c|c|c|}
\hline Category of intervention & Included interventions & $\begin{array}{l}\text { No of } \\
\text { patients }\end{array}$ & $\begin{array}{l}\text { No of } \\
\text { RCTs }\end{array}$ \\
\hline Incentive spirometry & Incentive spirometry \pm deep breathing exercises & 1940 & 6 \\
\hline $\begin{array}{l}\text { Prophylactic supervised } \\
\text { respiratory physiotherapy }\end{array}$ & $\begin{array}{l}\text { Prophylactic inspiratory muscle training, deep breathing exercise, and mobility pro- } \\
\text { grammes, conducted daily under supervision of physiotherapist for } \geq 3 \text { days, during } \\
\text { immediate pre/postoperative period }\end{array}$ & 1345 & 12 \\
\hline $\begin{array}{l}\text { Drug therapies to improve } \\
\text { pulmonary function }\end{array}$ & $\begin{array}{l}\text { Inhaled } \beta \text { agonists, inhaled steroid, inhaled mucolytic, prophylactic postoperative } \\
\text { antibiotics for respiratory infection, intraoperative magnesium infusion }\end{array}$ & 1032 & 8 \\
\hline $\begin{array}{l}\text { Intraoperative anaesthetic } \\
\text { gas composition }\end{array}$ & $\begin{array}{l}\text { High ( } 80 \%) \text { perioperative fractional inspired concentration of oxygen, nitrous oxide free } \\
\text { intraoperative inspired gas mixture }\end{array}$ & 3595 & 4 \\
\hline $\begin{array}{l}\text { Intraoperative ventilation } \\
\text { strategies }\end{array}$ & $\begin{array}{l}\text { High PEEP intraoperatively, ventilation strategies targeted to high or low tidal volumes per } \\
\text { unit body weight, intraoperative alveolar recruitment strategies, square wave inspiratory } \\
\text { flow pattern ventilation }\end{array}$ & 2132 & 18 \\
\hline $\begin{array}{l}\text { Prophylactic non-invasive } \\
\text { ventilation }\end{array}$ & $\begin{array}{l}\text { Prophylactic postoperative non-invasive ventilation, continuous positive air pressure, high } \\
\text { flow nasal cannula oxygen therapy }\end{array}$ & 1173 & 10 \\
\hline Analgesia techniques & $\begin{array}{l}\text { Thoracic epidural analgesia, patient controlled thoracic epidural analgesia, paravertebral } \\
\text { nerve block, preoperative non-steroidal anti-inflammatory drugs, intrapleural local } \\
\text { anaesthetic infusion, intrathecal opioid, intraoperative dexmedetomidine infusion }\end{array}$ & 3106 & 17 \\
\hline Lifestyle modifications & Smoking cessation therapy & 571 & 4 \\
\hline $\begin{array}{l}\text { Enhanced recovery after } \\
\text { surgery pathways }\end{array}$ & Protocolised enhanced recovery pathways & 519 & 5 \\
\hline $\begin{array}{l}\text { Perioperative fluid } \\
\text { administration }\end{array}$ & $\begin{array}{l}\text { Restrictive versus liberal perioperative fluid administration, goal directed haemodynamic } \\
\text { therapies }\end{array}$ & 4740 & 23 \\
\hline Miscellaneous & $\begin{array}{l}\text { Spinal } v \text { general anaesthesia, inhalational } v \text { intravenous general anaesthesia, breathing } \\
\text { system filter, comparison of neuromuscular blocking drugs, perioperative statin } \\
\text { use, supraglottic airway } v \text { endotracheal intubation, perioperative systemic warming, } \\
\text { endotracheal tube cuff design }\end{array}$ & 1786 & 10 \\
\hline
\end{tabular}

of included trials and individual meta-analysis of enhanced recovery after surgery interventions are provided in appendix 2, section 9.

\section{Prophylactic mucolytics}

The quality of evidence for prophylactic mucolytics was low. The mucolytic drug ambroxol was investigated in three RCTs including a pooled total of 452 surgical patients. ${ }^{33-35}$ Ambroxol reduces the viscosity of bronchial sputum, which may aid clearance. The dose of ambroxol was the same, at $1000 \mathrm{mg}$, in all studies,

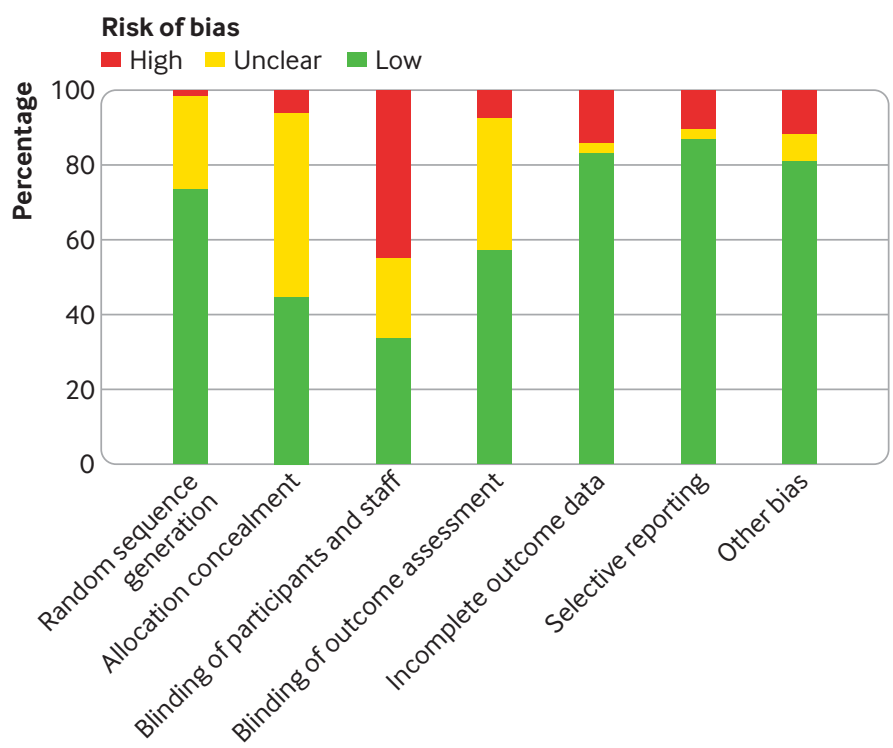

Fig 2 | Risk of bias graph showing each risk of bias item as percentages across all included studies varying in duration of daily administration from three to four postoperative days.

Meta-analysis showed a statistically significant benefit from ambroxol in reducing the risk of PPCs (risk ratio $0.40,0.23$ to 0.67 ), but the pooled sample size was small. Trial sequential analysis showed no firm evidence, indicating a risk of false positive meta-analysis results. Only very limited trial data on drug adverse effects, treatment compliance, pharmacovigilance, and safety were available. Hence, whether ambroxol should be recommended for routine prophylactic use is unclear from these data.

A recent, small study compared intravenous ambroxol, given on the day of surgery and for three postoperative days, against placebo in patients with pulmonary lobectomy. ${ }^{34}$ A larger study of 352 patients also found a reduction in PPCs in patients having abdominal surgery, predicated on a difference in atelectasis rather than respiratory infection. ${ }^{35} \mathrm{~A}$ further study, in patients undergoing video assisted thoracic surgery lobectomy or elective colorectal surgery, did not find any significant difference in PPCs between intervention and control groups. ${ }^{33}$ Full details of included trials and individual meta-analysis of drug therapies to improve pulmonary function are provided in appendix 2, section 3 .

\section{Prophylactic non-invasive ventilation}

The quality of evidence for prophylactic noninvasive ventilation was low. We identified six RCTs investigating single level continuous positive airway pressure $^{36-41}$ and two investigating bi-level pressure support ventilation, ${ }^{42}$ with a pooled total of 437 patients. These modes of ventilatory support use 


\begin{tabular}{|c|c|c|}
\hline Intervention & Relative effect: risk ratio $(95 \% \mathrm{Cl})$ & Quality of evidence \\
\hline Enhanced recovery pathways & 0.35 (0.21 to $\left.0.58 ; P<0.001 ;\left.\right|^{2}=0 \%\right)$ & Low \\
\hline Prophylactic mucolytics & 0.40 (0.23 to $\left.0.67 ; P<0.001 ;\left.\right|^{2}=0 \%\right)$ & Low \\
\hline Postoperative (continuous positive airway pressure) non-invasive ventilation & 0.49 (0.24 to $\left.0.99 ; P=0.05 I^{2}=48 \%\right)$ & Low \\
\hline Lung protective intraoperative ventilation & $0.52\left(0.30\right.$ to $\left.0.88 ; P=0.001 ; I^{2}=78 \%\right)$ & Moderate \\
\hline Prophylactic respiratory physiotherapy & $0.55\left(0.32\right.$ to $\left.0.93 ; P=0.02 ;\left.\right|^{2}=60 \%\right)$ & Low \\
\hline Epidural analgesia & $0.77\left(0.65\right.$ to $\left.0.92 ; P=0.003 ; I^{2}=0 \%\right)$ & Low \\
\hline Goal directed haemodynamic therapy & $0.87\left(0.77-0.98 ; P=0.02 ; 1^{2}=0 \%\right)$ & Moderate \\
\hline
\end{tabular}

positive pressure to splint open airways and improve work of breathing through improvement in respiratory system compliance and augmentation of inspiratory effort. An additional 330 patients were included in trials of high flow nasal continuous oxygen devices, which were analysed separately.

In the studies of continuous positive airway pressure, a positive end expiratory pressure of at least $8 \mathrm{~cm} \mathrm{H}_{2} \mathrm{O}$ was applied without interruption for at least eight to 12 hours following extubation or admission to a post-anaesthetic care unit. ${ }^{36}{ }^{38}$ Meta-analysis suggests that starting continuous positive airway pressure prophylactically in the postoperative period for major abdominal and thoracic surgical patients may reduce PPCs (risk ratio $0.49,0.24$ to 0.99); however, included RCTs were small and the cumulative $\mathrm{z}$ curve did not cross the calculated trial sequential monitoring boundary. This positive effect on PPC outcomes may therefore may be a false positive, and further trials are likely to change our results. Evidence of a clinical effect was not replicated in trials of bi-level non-invasive ventilation or high flow nasal continuous oxygen, which exerts a similar (but lower magnitude) airway splinting effect to continuous positive airway pressure. ${ }^{44}$ The largest trial of bi-level non-invasive ventilation did not show any difference in PPCs between treatment and control groups in thoracic surgical patients. ${ }^{42}$

Four of the studies included only thoracic surgical patients, ${ }^{37424345}$ with two studying patients undergoing thoracoabdominal vascular repairs via a midline laparotomy, ${ }^{3841}$ and two RCTs including elective upper abdominal surgical patients. ${ }^{3940}$ Both trials of high flow nasal cannulas included patients with an intermediate to high predictive risk of PPCs (assessed as an ARISCAT score $\geq 26^{8} 46$ ), with one study recruiting a mixed population of emergency and elective abdominal and thoracic procedures, ${ }^{28}$ and one study recruiting only thoracic thoracoscopic lobectomy patients. ${ }^{45}$

All of the included RCTs featured intervention strategies that were started prophylactically on the same day as surgery. Variation was evident in terms of the time between postoperative extubation and start of non-invasive ventilation, the ventilator equipment used, and the intensity and duration of ventilation. Nasal continuous positive airway pressure masks were used in two RCTs ${ }^{3841}$ with face or helmet masks in all other studies. Levels of inspiratory and expiratory

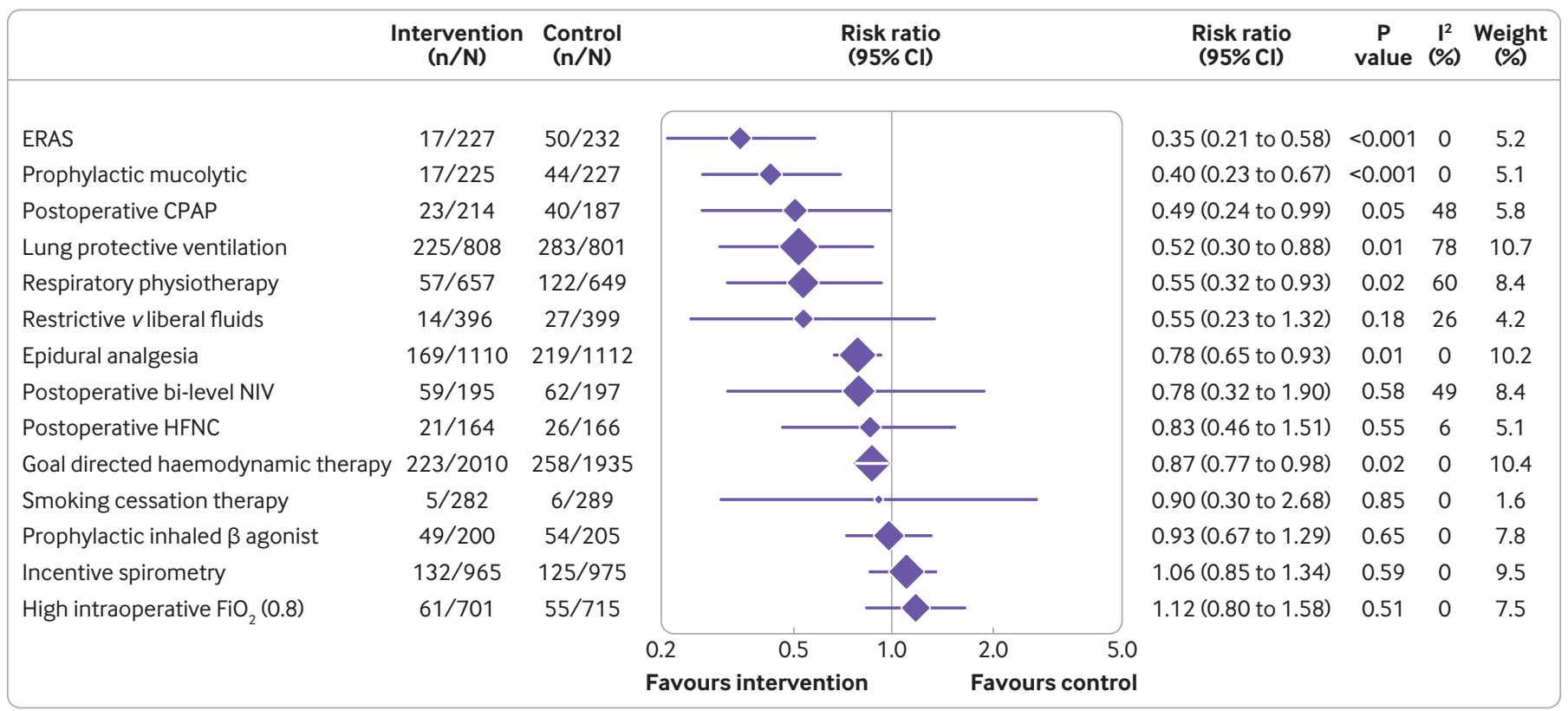

Fig 3 | Forest plot of strategies for efficacy in reducing risk of postoperative pulmonary complications (PPCs). Strategies were tested with standard medical care as control. $C P A P=$ continuous positive airway pressure; $E R A S=e n h a n c e d$ recovery after surgery; $\mathrm{FiO}_{2}=$ fractional inspiration oxygen; HFNC=high flow nasal cannula; $n=$ number of patients with PPC outcome in each group; $N=$ total number of patients in each group; NIV=non-invasive ventilation 


\begin{tabular}{|c|c|c|c|c|}
\hline Category of intervention & $\begin{array}{l}\text { Information size in } \\
\text { meta-analysis }\end{array}$ & $\begin{array}{l}\text { Trial sequential monitoring } \\
\text { boundary crossed }\end{array}$ & DARIS & Result \\
\hline Incentive spirometry & 1940 & No & 3055 & Inconclusive \\
\hline Prophylactic supervised respiratory physiotherapy & 1345 & Yes & 6155 & Firm evidence \\
\hline Prophylactic mucolytic & 452 & No & 1888 & Inconclusive \\
\hline CPAP/BIPAP & 437 & No & 7577 & Inconclusive \\
\hline Epidural & 2494 & Yes & 3058 & Firm evidence \\
\hline Smoking cessation & 571 & No & 20748 & Inconclusive \\
\hline Enhanced recovery after surgery pathways & 459 & Yes & 1653 & Firm evidence \\
\hline Goal directed haemodynamic therapy & 3945 & Yes & 2911 & Firm evidence \\
\hline
\end{tabular}

pressure varied, and in the most recent large pragmatic RCT of bi-level positive airway pressure, ${ }^{42}$ parameters were defined by responsible physicians, alongside choice of masks, adjustment of ventilator settings, and initial patient set-up. Both trials of high flow nasal cannulas used warmed, humidified circuits provided by the Optiflow system (Fisher and Paykel Healthcare Ltd, Auckland, New Zealand), with oxygen flow rates and fractional inspiration concentration titrated by bedside clinical staff to maintain oxygen saturation at $95 \%$ or above.

Duration of ventilatory support ranged from two 120 minute cycles of helmet continuous positive airway pressure on the first postoperative day only to bi-level positive airway pressure provided preoperatively for seven days and then daily during the postoperative inpatient stay. ${ }^{43}$ Five of the nine trials involved provision of the intervention for less than 24 hours, ${ }^{2836-3841}$ and one trial for three days, ${ }^{40}$ whereas the remainder continued to provide ventilator support while patients were in hospital. ${ }^{39} 424345$ Full details of included trials and individual meta-analysis of prophylactic non-invasive ventilation are provided in appendix 2, section 6 .

\section{Lung protective ventilation}

Seven RCTs including a pooled total of 1609 participants investigated the effect of lung protective intraoperative ventilation strategies on PPCs. ${ }^{47-53}$ The definition of lung protective ventilation varied between trials, but for the purposes of analysis we used a single definition of reduced tidal volumes $(\leq 8 \mathrm{~mL} / \mathrm{kg})$ and at least $5 \mathrm{~cm} \mathrm{H}_{2} \mathrm{O}$ positive end expiratory pressure together with intermittent recruitment manoeuvres. Statistical heterogeneity was high $\left(\mathrm{I}^{2}=78 \%\right)$, and the quality of evidence for this intervention was moderate. Meta-analysis showed a significant treatment effect of lung protective ventilation on PPC outcomes (risk ratio $0.52,0.30$ to 0.88 ). Although the cumulative $z$ curve crossed the conventional monitoring boundaries, the trial sequential monitoring boundaries were not crossed. Hence, no firm evidence suggested that lung protective ventilation could effect a $25 \%$ relative risk reduction in PPCs and further trials are still needed.

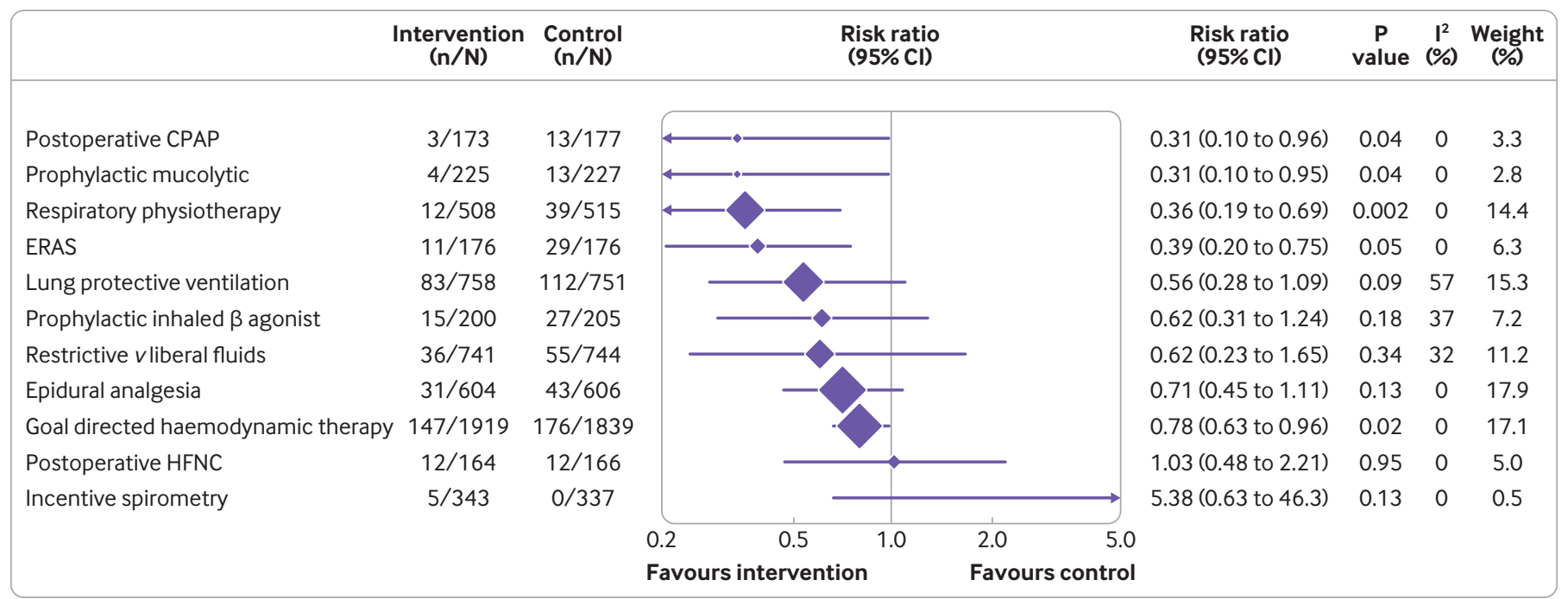

Fig 4 | Forest plot of strategies for efficacy in reducing risk of respiratory infection. Strategies were tested with standard medical care as control. $\mathrm{CPAP}=$ continuous positive airway pressure; $\mathrm{ERAS}=$ enhanced recovery after surgery; $\mathrm{HFNC}=$ high flow nasal cannula; $\mathrm{n}=$ number of patients with respiratory infection outcome in each group; $\mathrm{N}=$ total number of patients in each group 


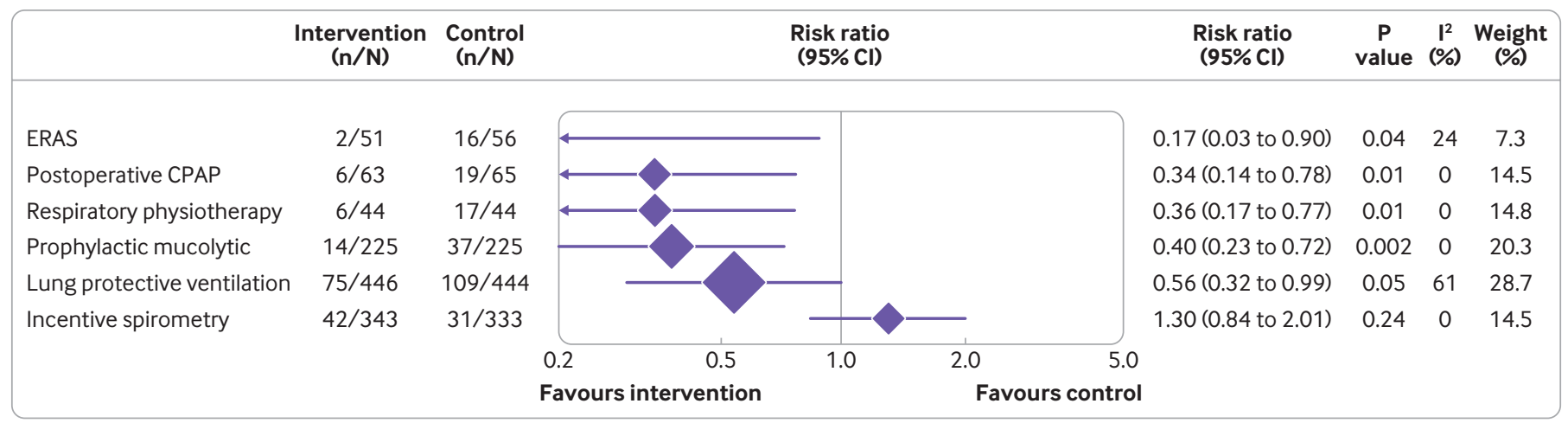

Fig 5 | Forest plot of strategies for efficacy of reducing risk of atelectasis. Strategies were tested with standard medical care as control.

$\mathrm{CPAP}=$ continuous positive airway pressure; $E R A S=$ enhanced recovery after surgery; $n=$ number of patients with atelectasis outcome in each group; $\mathrm{N}=$ total number of patients in each group

In total, 18 RCTs investigating different aspects of intraoperative ventilation were identified in this review, ${ }^{47-64}$ including a pool of 2171 patients. Seven studies were of patients having open abdominal surgery, ${ }^{47}$ 49-51 545664 five were of exclusively minimally invasive surgery (laparoscopic or robotic), 5255 58-60 three were of lung cancer resection surgery (open or thoracoscopic), ${ }^{485761}$ one was of neurosurgery, ${ }^{62}$ one was obstetric, ${ }^{53}$ and one recruited patients from a range of specialties united in having prolonged surgery. ${ }^{63}$

Four studies primarily investigated the role of different levels of positive end expiratory pressure, recruiting a total of 1073 patients. Four studies explored the use of different target tidal volumes, recruiting 244 patients. A single centre study recruited 44 patients having open lung resection, and one lung (the non-dependent one) was either ventilated with high frequency percussive ventilation or received continuous positive airway pressure. ${ }^{61}$ Although some mechanistic variables were improved, we saw no reduction in PPC for any of these interventions.

The largest trial was the PROVHILO study, ${ }^{51}$ which recruited 894 patients from 30 international hospitals and compared high positive end expiratory pressure (12 $\mathrm{cm} \mathrm{H}_{2} \mathrm{O}$ ) with recruitment manoeuvre versus low positive end expiratory pressure $\left(\leq 2 \mathrm{~cm} \mathrm{H}_{2} \mathrm{O}\right)$ in patients having major abdominal surgery and at increased risk of PPCs. No beneficial treatment effect was found in PROVHILO, but the smaller IMPROVE study randomised 400 patients at increased risk of PPCs and showed a significant reduction in PPCs with lung protective ventilation. ${ }^{50}$

In contrast to the benefit found when protective ventilatory strategies were combined, only one small study of $5 \mathrm{~mL} / \mathrm{kg}$ versus an $8 \mathrm{~mL} / \mathrm{kg}$ tidal volume control group during single lung ventilation of patients undergoing minimally invasive oesophagectomy found a reduction in PPCs in the intervention group. ${ }^{58}$ Full details of included trials and individual meta-analysis of intraoperative ventilation strategies are provided in appendix 2, section 5 .

\section{Respiratory physiotherapy}

Respiratory physiotherapists train and supervise patients in sputum clearance, developing inspiratory muscle strength, and deep breathing exercises. Prophylactic application of these techniques may improve respiratory endurance and expel pulmonary secretions, thereby reducing the risk of PPCs. A total of 12 RCTs including a pooled total of 1345 patients undergoing abdominal and thoracic surgical procedures investigated the application of prophylactic supervised respiratory physiotherapy. ${ }^{65-76}$ The quality of the evidence was low. Physiotherapy regimens varied between trials and included both preoperative and postoperative interventions. Meta-analysis

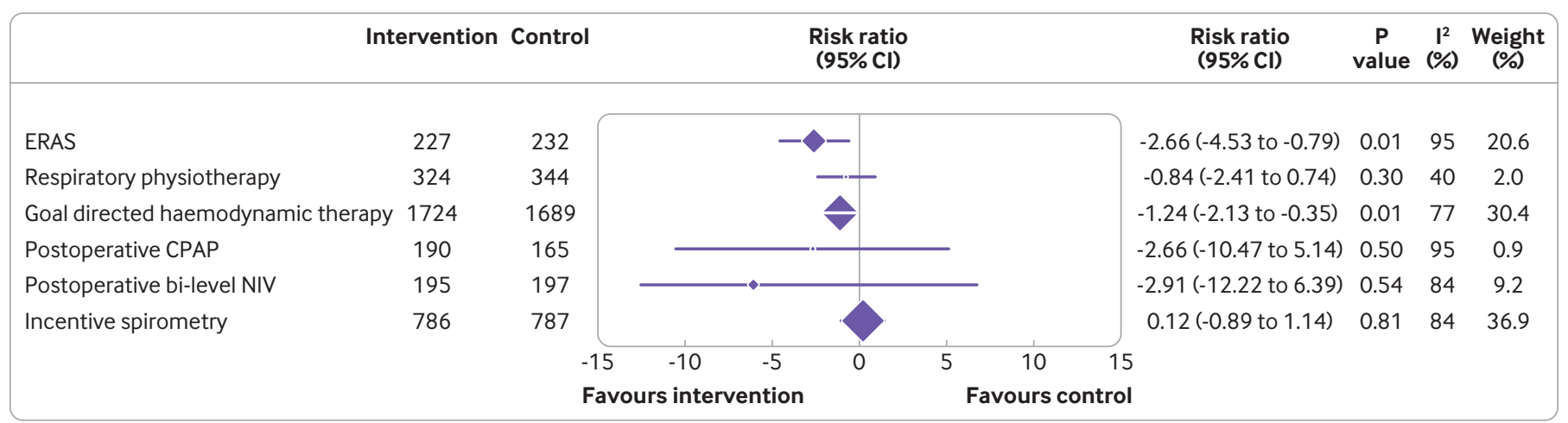

Fig 6 | Forest plot of hospital length of stay for strategies investigated to reduce postoperative pulmonary complications. Strategies were tested with standard medical care as a control. CPAP=continuous positive airway pressure; $E R A S=e n h a n c e d$ recovery after surgery; $N I V=n o n$-invasive ventilation 


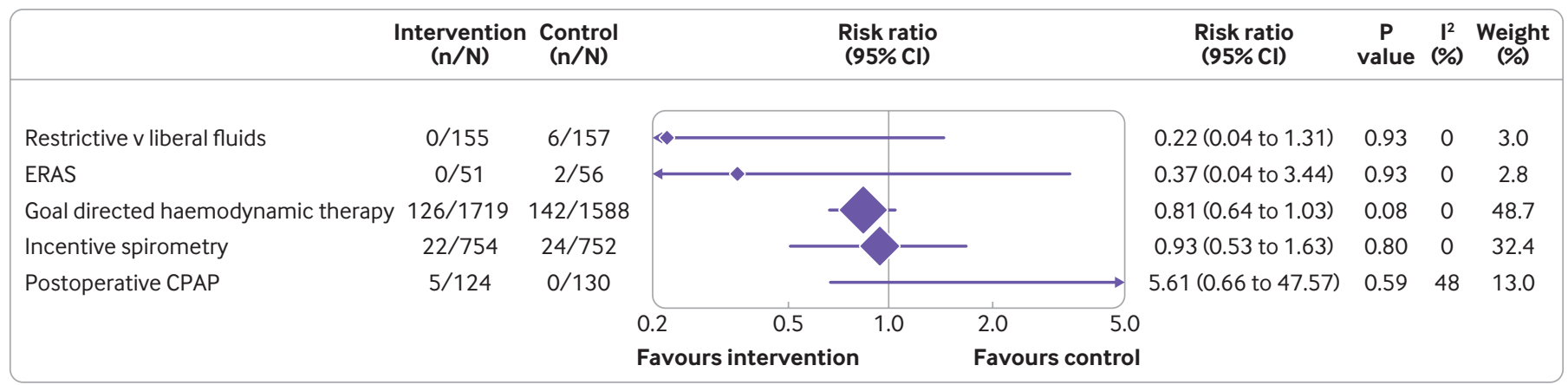

Fig 7 | Forest plot of mortality for strategies investigated to reduce postoperative pulmonary complications. Strategies were tested with standard medical care as control. $\mathrm{CPAP}=$ continuous positive airway pressure; ERAS=enhanced recovery after surgery; $n=$ number of patients with mortality outcome in each group; $\mathrm{N}=$ total number of patients in each group; $\mathrm{NIV}=$ non-invasive ventilation

of pooled results from 11 RCTs showed an overall benefit (risk ratio $0.55,0.32$ to 0.93 ) of prophylactic physiotherapy in reducing the development of PPCs. Trial sequential analysis supported the meta-analysis findings, indicating that the information size was sufficient to find firm evidence of a $25 \%$ relative risk reduction in PPCs.

Risk of bias was high; in particular, overall study quality was reduced by the lack of blinding of patients to intervention allocation, crossover between group allocations (with control group patients receiving physiotherapy ad hoc), and a high loss to follow-up in several of the studies. Furthermore, study sample sizes were small, with only three RCTs featuring intervention or control group sizes of more than 50 patients each. ${ }^{666871}$

Patients undergoing a variety of surgical procedures were studied, including elective thoracic surgery, ${ }^{717376}$ elective open abdominal aortic aneurysm repairs, ${ }^{67}$ unselected elective open abdominal surgery, ${ }^{66} 7072$ and upper abdominal surgery. ${ }^{6568} 697475$ Only one study included laparoscopic surgical patients (with a corresponding lower reported proportion of PPCs in both intervention and control groups than for other studies), ${ }^{69}$ and the remainder were open procedures.

A large variety of physiotherapy regimens were tested in the included studies, although all incorporated instruction and supervision of patients by a trained physiotherapist for at least three preoperative or postoperative days. Three studies included preoperative inspiratory muscle training. ${ }^{67} 7075$ Eight studies including postoperative supervision across a range of deep breathing exercises, coughing exercises, assistance with ambulation, and inspiratory muscle training. ${ }^{65666971-7476}$ Only one study included patients receiving both preoperative and postoperative exercises supervised by physiotherapists. ${ }^{68}$ Comparator groups were standard care only, in which physiotherapy was withheld unless requested by a clinician or unless a PPC developed, with the exception of one study in which low intensity preoperative physiotherapy training was compared with high intensity physiotherapy. ${ }^{75}$

Most(11/12) trials reported no benefit of prophylactic physiotherapy for PPC outcomes. However, the largest and highest quality RCT, ${ }^{68}$ which included preoperative and postoperative physiotherapy exercises, showed a significant difference in the proportion of patients developing PPCs after elective major abdominal surgery $(10 / 172(6 \%)$ in the intervention group and $52 / 192(27 \%)$ in the control group; $\mathrm{P}<0.001)$. Full details of included trials and individual meta-analysis of supervised respiratory physiotherapy are provided in appendix 2, section 2.

\section{Epidural analgesia}

Eleven studies investigated epidural analgesia against patient controlled analgesia with morphine, with a pooled total of 2494 patients. ${ }^{77-87}$ The quality of the evidence was low. Meta-analysis showed a benefit in PPC outcomes with use of epidural analgesia (risk ratio $0.78,0.65$ to 0.93 ), and the information size was sufficient in trial sequential analysis to draw firm conclusions of a $25 \%$ relative risk reduction. Most trials were for abdominal procedures, although two studies included thoracic procedures. ${ }^{81} 83$ Variability existed in the time point for starting epidural analgesia, regimens, and constituents of infusion, although epidurals routinely remained in situ for 72 hours postoperatively. The MASTER trial, ${ }^{81}$ which focused on surgical patients at high risk, had significant weighting in the meta-analysis (63.5\%); if this was removed, the risk reduction with epidurals would not be apparent. Full details of included trials and individual metaanalysis of all analgesic strategies (including epidural analgesia) are provided in appendix 2, section 7 .

\section{Goal directed haemodynamic therapy}

Goal directed haemodynamic therapy was investigated in 14 studies, with a pooled total of 3945 patients. ${ }^{88-101}$ Goal directed haemodynamic therapy involves individualised perioperative fluid, inotrope, or vasopressor administration to achieve pre-defined biological targets (such as calculated oxygen delivery, pulmonary capillary wedge pressure, or cardiac stroke volume variation). Moderate quality evidence showed a small treatment effect (risk ratio 0.87, 0.77 to 0.98); however, the limited data available did not suggest superiority of any specific haemodynamic goal. We found firm evidence of superiority for the goal directed haemodynamic therapies (based on a 25\% relative risk 
reduction) in trial sequential analysis. Conversely, we found no significant benefit in our meta-analysis of nine trials of 795 patients for restrictive versus liberal fluid volume based administration strategies. ${ }^{102-110}$

Subgroup analysis of five studies in which goal directed haemodynamic therapy consisted solely for trials of fluid administration interventions (that is, without the additional use of vasoactive drugs) included a pooled total of 557 patients. ${ }^{91} 92969799$ Moderate quality evidence showed a more pronounced treatment effect of goal directed fluid therapy compared with studies in which fluids were used in combination with vasoactive drugs. Full details of included trials and individual meta-analysis of perioperative fluid administration and goal directed haemodynamic therapies are provided in appendix 2, section 10.

\section{Narrative review of miscellaneous interventions}

A total of 22 RCTs were identified by the review but were unsuitable for pooling of data with data from other trials either because the interventions were dissimilar or because interventions were evaluated in a single trial only. Full details of all trials are included in appendix 2.

Several interventions were included in the miscellaneous category, including a trial showing a reduction of PPCs (but not respiratory infections) in patients receiving maintenance inhalational anaesthesia (with sevoflurane) compared with those receiving propofol total intravenous anaesthesia for lung cancer surgery. ${ }^{111}$ One randomised pilot study measured postoperative complications in older patients having general anaesthesia versus spinal anaesthesia for hip fracture surgery in a single centre in the UK. ${ }^{112}$ The study showed no difference in the risk of PPCs between the groups.

The role of neuromuscular blockade during surgery was evaluated in two studies. One RCT investigated the effect of different neuromuscular blocking drugs on residual muscular weakness at the end of surgery and PPCs. ${ }^{113} \mathrm{~A}$ second trial investigated whether sugammadex (at a dose of $2-4 \mathrm{mg} / \mathrm{kg}$ ) reduced the incidence of PPCs compared with conventional reversal of intraoperative neuromuscular blockade (neostigmine and glycopyrrolate). ${ }^{114}$ In the first trial, significantly more patients in the pancuronium group than in the atracurium or vecuronium groups showed residual neuromuscular block. The incidence of PPCs was higher in patients with residual neuromuscular block who received pancuronium, but no significant difference in PPCs was seen in patients with or without residual block for the atracurium or vecuronium groups. The second trial of sugammadex showed no significant difference in PPCs between reversal groups (risk ratio $0.26,0.03$ to $2.27 ; \mathrm{P}=0.22$ ).

Perioperative systemic warming was investigated in more than 60 randomised trials, but only one reported discrete PPC outcomes. ${ }^{115}$ This single trial identified no significant difference in PPCs between an intervention group receiving extended perioperative warming and a group receiving intraoperative warming only. Likewise, a trial of different endotracheal tube cuff designs (spherical or taped) in surgical patients did not show any significant difference in PPC outcomes, ${ }^{116}$ and nor did a trial on the presence or absence of a breathing system filter during intraoperative ventilation. ${ }^{117}$ Two trials investigated whether a supraglottic airway device or endotracheal tube was superior for reducing PPCs in patients undergoing laparoscopic surgery. ${ }^{118} 119$ No difference was seen in meta-analysis (risk ratio 3.08, 0.13 to 74.41). Finally, four studies reported on non-epidural analgesic techniques consisting of nerve blocks, intrathecal opiates, and intravenous dexmedetomidine. ${ }^{120-123}$ None of the non-epidural analgesic studies reported any difference in PPCs between control and intervention groups. Most of the above trials reported PPCs as a secondary outcome measure only and were underpowered for PPC outcomes.

\section{Discussion}

Our study identified 11 categories of perioperative care interventions that have been tested in randomised trials with the aim of reducing PPCs. Our main finding is that despite a huge literature and the clinical prevalence and importance of the outcome, the existing evidence is of generally poor quality and does not give definitive answers. None of the interventions we evaluated was supported by high quality evidence. Only one-goal directed fluid therapy-was supported both by moderate quality evidence and trial sequential analysis. One further intervention-lung protective intraoperative ventilation-was supported by moderate quality evidence, but trial sequential analysis indicated that further data would be needed for us to be confident of this. A further five interventions had low quality evidence of treatment benefit: enhanced recovery pathways, prophylactic mucolytics, postoperative continuous positive airway pressure ventilation, prophylactic respiratory physiotherapy, and epidural analgesia. Trial sequential analysis indicated a risk of false positive results for continuous positive airway pressure and mucolytics for a relative risk reduction of $25 \%$.

\section{Intervention effect sizes}

Effect sizes of relative risk reduction for interventions were generally small to moderate (table 8 ), with the exception of enhanced recovery pathways, for which it was disproportionately large but based on trials with a high risk of bias. Interventions investigated in higher risk cohorts, with a higher baseline proportion of PPCs in controls groups, were more likely to show significant benefit, but the findings may not be generalisable to lower risk cohorts. Given the relatively high prevalence of PPCs (14.4\% of all patients included in this review) and their associations with longer term outcomes, ${ }^{9}$ the potential effect that effective treatments may offer in improving perioperative healthcare provision is large. PPCs have implications for healthcare costs, primarily as a result of increased length of hospital stay. ${ }^{124}$ A retrospective study found that surgical 
patients in a Canadian tertiary hospital who developed postoperative pneumonia had 55\% higher costs and $89 \%$ longer hospital stays. ${ }^{125}$ PPCs therefore represent a major opportunity for improved outcomes for patients and financial savings, with evidence of beneficial preventive measures reducing mortality, morbidity, and the cost of a surgical procedure.

\section{Lung protective ventilation}

Lung protective ventilation describes strategies to adjust the ventilator intraoperatively to minimise lung injury. We found a significant treatment effect on PPCs, and despite inclusion of different trials, our effect was consistent with those of other meta-analyses and systematic reviews of lung protective ventilation. ${ }^{126-130}$ However, our trial sequential analysis did not find that the accumulated information size was sufficient to draw firm conclusions on a $25 \%$ relative risk reduction, so further trials are still needed. Our definition of lung protective ventilation covered a range of interventions that were sufficiently similar to be grouped together: all trials included use of positive end expiratory pressure of at least $5 \mathrm{~cm} \mathrm{H}_{2} \mathrm{O}$ and tidal volume of no more than 8 $\mathrm{mL} / \mathrm{kg}$ predicted body weight, and all but one included some form of recruitment manoeuvre (a short period of high pressure applied to the lungs to inflate them more fully). ${ }^{48}$ Although recruitment manoeuvres have good physiological rationale for optimising pulmonary compliance, they may cause harm through their effects on the circulation. ${ }^{131}$ In the high quality and relatively recent PROVHILO trial (which showed no benefit of lung protective ventilation on the primary outcome of PPCs), ${ }^{51}$ any beneficial effects of the recruitment manoeuvres on the lungs were probably outweighed by the adverse effects on the circulation. A disadvantage of comparing two extreme values of positive end expiratory pressure (low versus high) is that each patient may have an optimal positive end expiratory pressure that is neither of these. Aiming to identify optimal positive end expiratory pressure for an individual patient has been evaluated in a proof of concept study, ${ }^{132}$ which was followed by a large multicentre RCT (iPROVE, published subsequently to our search dates). iPROVE studied 1012 patients receiving abdominal surgery and at moderate to high risk of PPCs, and no benefit was seen in those receiving individually optimised ventilation. ${ }^{133}$ All patients in this study received many of the elements of lung

\begin{tabular}{|c|c|c|}
\hline Category of intervention & NNT $(95 \% \mathrm{Cl})$ & GRADE quality of evidence \\
\hline Enhanced recovery after surgery pathways & 8 (4.9 to 12.9$)$ & Low \\
\hline Prophylactic mucolytic & $9(5.5$ to 17.8$)$ & Low \\
\hline Postoperative CPAP & $10(5.6$ to 29$)$ & Low \\
\hline Lung protective ventilation & 14 (8.3 to 33.8$)$ & Moderate \\
\hline Respiratory physiotherapy & $10(7.2$ to 15.6$)$ & Low \\
\hline Epidural analgesia & $22(13.4$ to 59.7$)$ & Low \\
\hline Goal directed haemodynamic therapy & $45(23.3$ to 514.1$)$ & Moderate \\
\hline
\end{tabular}

protective ventilation, and, in this context, the additive benefit of optimising positive end expiratory pressure may not be apparent. Although lung protective ventilation is a particularly attractive intervention, as it has no associated financial cost, the fidelity of its implementation in routine practice (as described in large scale audit data from the US and the $\mathrm{UK}^{134-136}$ ) is often disappointing.

\section{Goal directed haemodynamic therapy}

Goal directed haemodynamic therapy aims to improve oxygen delivery to the tissues through the optimisation of end organ perfusion and has moderate quality evidence of a reduction in PPCs. Goal directed haemodynamic therapy can be achieved by the use of vasoactive drugs, fluids, or both, dosed according to the response of specific physiological parameters in individual patients, towards a pre-defined goal. Trials of goal directed haemodynamic therapy have shown a reduction in several postoperative complications, and our meta-analysis confirms this specifically for pulmonary complications. In this study, a subgroup meta-analysis of trials that relied solely on the administration of fluids (goal directed fluid therapy) for haemodynamic optimisation without the use of vasoactive drugs shows a reduction in the risk of PPCs (risk ratio $0.47,0.32$ to $0.71 ; \mathrm{P}=0.001$ ). This finding suggests that goal directed fluid alone, without the addition of vasoactive drugs, also has a protective effect on the lungs.

Trials comparing restrictive and liberal fluid management strategies have shown that restrictive fluid regimens have been associated with an increased risk of acute kidney injury, ${ }^{137}$ whereas liberal regimens have been associated with fluid overload and pulmonary congestion, poor wound healing, and paralytic ileus. ${ }^{9194105}$ Neither liberal nor restrictive fluid strategies are protective against PPCs. Our metaanalysis showed a reduction in length of hospital stay with restrictive fluid regimens, but with a small effect size. Arguably, in many of the included studies, the volumes of fluid administered, even to patients in the restrictive groups, is excessive compared with the volumes administered in the goal directed haemodynamic therapy trials.

A recently published multicentre RCT from Spain (FEDORA, ${ }^{138}$ published subsequently to our search dates and therefore not included in the meta-analysis) of goal directed haemodynamic therapy versus standard care in patients at lower risk undergoing major surgery showed a statistically significant reduction in PPCs (and other complications) and reduced length of hospital stay. The benefits were exclusively seen in patients having abdominal surgery, and this is relevant as the ongoing OPTIMISE-II study is exclusively recruiting patients undergoing major gastrointestinal surgery. ${ }^{139}$

\section{Role for care bundles?}

Substantial changes in the perioperative care of patients have occurred in the past decade. An 
increasingly popular and evidence based approach to minimise the risk of complications in surgical and medical patients is the adoption of care bundles. Care bundles are collections of evidence based practices (ideally no more than five interventions in one bundle), which when performed together result in better outcomes than when applied individually. Recent research from our group has clarified important principles for care bundles ${ }^{140}$ : interventions within a care bundle should reflect best practice, bundles with a small number of simple elements have better compliance rates, bundles should also be used to guide teamwork in achieving care delivery, and measurement of success is binary-all of the individual interventions need to be implemented together in a single patient for delivery of the bundle to be considered compliant. Such bundles have already been shown to reduce some postoperative complications, ${ }^{141}$ particularly surgical site infection. ${ }^{142} 143$

Despite care bundles being strongly endorsed for prevention of ventilator associated pneumonia in intensive care, ${ }^{144} 145$ evidence for equivalent nonventilator bundles in perioperative patient care to prevent PPCs is still uncertain. ${ }^{146}$ An international Delphi consensus process considered which interventions might best be combined to reduce PPCs, ${ }^{147}$ and a UK based, patient centred quality improvement project (ERAS+) used a PPC reduction care bundle with notable success. ${ }^{148}$ To date, these care bundles have predominantly included relatively simple and inexpensive interventions, often with imperfect evidence of efficacy. Ideally, the interventions within a care bundle would have robust supportive evidence and interact with each other synergistically. We propose that the evidence from this review be used to guide development of care bundles for prevention of PPCs, although we acknowledge that further research is needed to determine the ideal components of PPC bundles and establish evidence of effectiveness.

\section{Implications for research}

The most common reason for RCTs to be excluded from the analysis phase of this review was a lack of reported clinical PPC outcomes, with many trials using more easily measured surrogate recordings such as lung spirometry tests instead. We suggest that clinically detectable pathology, such as PPCs, is more meaningful to patients and should be used to design relevant future research. Trials should use standardised definitions for PPCs, such as the EPCO criteria or the recently published standardised endpoints in perioperative medicine (StEP) initiative PPC definitions. ${ }^{118}$

Likewise, although this review evaluates the best available RCT evidence for PPCs, other forms of evidence are available. For example, the adverse influence of neuromuscular blocking drugs is now well established, ${ }^{149-153}$ especially when they are associated with inadequate reversal (a train of four ratio of $<0.9$ ). Furthermore, active intraoperative warming, airway suctioning, and choice of airway device are all relevant interventions with an effect on PPCs. However, most of the above interventions have been predominantly studied in observational, rather than randomised, trial designs or with evidence translated from critical care, rather than surgical, patient cohorts. Hence, the pool of randomised studies of adult surgical patients with clinical outcomes for several of the interventions was surprisingly small. The results from this review therefore need to be interpreted in the context of other forms of relevant evidence and clearly indicate a role for large, well designed propensity score studies in best understanding the role of intraoperative interventions that are challenging to study in RCTs.

\section{Strengths and limitations of review}

Using robust and standardised methods including GRADE methods and pre-specified analyses, we comprehensive reviewed a vast literature spanning anaesthesia, surgery, and respiratory and intensive care medicine. This included meta-analysis of treatment effects and trial sequential analysis. We used trial sequential analysis to explore the risk of random error as a result of sparse data and repetitive testing in order to increase the robustness of the meta-analyses and distinguish the current information size from the required information size.

However, in our study, and in general, the literature evaluating interventions to reduce PPCs is limited by several factors. The quality of trials was mixed, with only a minority being large, multicentre studies with a low risk of bias. Heterogeneity of trial design and outcome measures used, and variation in surveillance fidelity and diagnostic classifications for PPC outcomes, pose a problem for evidence synthesis. We anticipated heterogeneity and used random effect model analysis and trial sequential analysis to provide conservative estimates of treatment effects and reduce false positives.

As a composite measure, PPCs do not convey the precise nature of complications that are experienced by patients. One intervention may have a relatively larger effect on atelectasis than on respiratory infection, for example. For this reason, we specifically evaluated the individual outcomes of respiratory infection, atelectasis, mortality, and length of hospital stay in our meta-analyses.

The quality of the literature we evaluated was also limited by imprecise and varying descriptions of the interventions. We identified significant heterogeneity in several aspects of the included trials, such as precise terms, timings and limits of tested interventions, characteristics of participants in trials, surgery type, outcome measurement timings and definitions, and other factors that might influence PPCs such as fluid therapy, analgesia types, and smoking status. This information was also not universally available for the patients included in the trials we analysed.

We have focused on the evidence of efficacy in reducing PPCs and not taken into consideration other factors that would be necessary to evaluate effectiveness or whether these interventions would be suitable to introduce, either in isolation or within a "care bundle." The breadth of this review, in terms 
of number of trials and range of interventions studied, necessarily meant that we were unable to compare individual adverse effects. Adverse effects were often intervention specific and lacked a common outcome framework between trials. We have also not considered the costs of the interventions, nor their tolerance, concordance, or acceptability for patients.

\section{Conclusions}

We have shown that the best quality evidence is in favour of lung protective ventilation and perioperative goal directed haemodynamic therapy in reducing PPCs. Some interventions that are commonly used, sometimes within care bundles, lack supportive evidence. Despite a large number of patients enrolled in many studies in this area, the evidence base is often of low quality and is both diverse and conflicting.

Several large trials that are in progress, or soon to start, will add to our understanding of the role of perioperative goal directed haemodynamic therapy, continuous positive airway pressure, and inspiratory muscle training. ${ }^{139} 154155$ Although it is challenging, trialists should attempt to use standardised endpoints (for both efficacy and adverse effects) and consider aspects relating to the cost and acceptability of interventions. These data are needed to enable the best synthesis of the evidence for making recommendations and informing clinical practice.

Contributors: SRM, PMO, and SB had the idea for the study. PMO and SB designed the search strategy. PMO, SB, and DG screened abstracts and full texts, acquired data, and assessed risk of bias in studies. PMO did the data analysis. SRM and BCB helped to coordinate the review and critically reviewed the manuscript. All authors interpreted the data analysis. PMO wrote the manuscript, with revisions from all authors. The corresponding author attests that all listed authors meet authorship criteria and that no others meeting the criteria have been omitted. PMO is the guarantor.

Funding: None.

Competing interests: All authors have completed the ICMIE uniform disclosure form at www.icmje.org/coi_disclosure.pdf and declare: no support from any organisation for the submitted work; no financial relationships with any organisations that might have an interest in the submitted work in the previous three years; no other relationships or activities that could appear to have influenced the submitted work.

Ethical approval: Not required.

Data sharing: No additional data available

Transparency: The lead author affirms that the manuscript is an honest, accurate, and transparent account of the study being reported; that no important aspects of the study have been omitted; and that any discrepancies from the study as planned (and, if relevant, registered) have been explained.

Dissemination: We plan to disseminate the results of the published study widely through traditional media and social media, using the communications offices of our respective hospitals and universities Other dissemination includes presentation at scientific meetings. We have no way of directly contacting the original trial participants. No plans exist to involve members of the public in dissemination. However, for this paper we are expanding our dissemination by writing a $B M$ J perspective article with a patient about our research

This is an Open Access article distributed in accordance with the Creative Commons Attribution Non Commercial (CC BY-NC 4.0) license, which permits others to distribute, remix, adapt, build upon this work non-commercially, and license their derivative works on different terms, provided the original work is properly cited and the use is noncommercial. See: http://creativecommons.org/licenses/by-nc/4.0/.

1 Jammer I, Wickboldt N, Sander M, et al, European Society of Anaesthesiology (ESA) and the European Society of Intensive Care Medicine (ESICM), European Society of Anaesthesiology, European
Society of Intensive Care Medicine. Standards for definitions and use of outcome measures for clinical effectiveness research in perioperative medicine: European Perioperative Clinical Outcome (EPCO) definitions: a statement from the ESA-ESICM joint taskforce on perioperative outcome measures. Eur J Anaesthesiol 2015;32:88 105. doi:10.1097/EJA.0000000000000118

2 Warner DO. Preventing postoperative pulmonary complications: the role of the anesthesiologist. Anesthesiology 2000;92:1467-72 doi:10.1097/00000542-200005000-00037

3 Lawrence VA, Hilsenbeck SG, Mulrow CD, Dhanda R, Sapp J, Page CP. Incidence and hospital stay for cardiac and pulmonary complications after abdominal surgery. J Gen Intern Med 1995;10:671-8. doi:10.1007/BF02602761

4 Yang CK, Teng A, Lee DY, Rose K. Pulmonary complications after major abdominal surgery: National Surgical Quality Improvement Program analysis. J Surg Res 2015;198:441-9. doi:10.1016/j. jss.2015.03.028

5 McAlister FA, Bertsch K, Man J, Bradley J, Jacka M. Incidence of and risk factors for pulmonary complications after nonthoracic surgery. Am J Respir Crit Care Med 2005;171:514-7. doi:10.1164/ rccm.200408-10690C

6 Smith PR, Baig MA, Brito V, Bader F, Bergman MI, Alfonso A. Postoperative pulmonary complications after laparotomy. Respiration 2010;80:269-74. doi:10.1159/000253881

7 Canet J, Sabaté S, Mazo V, et al, PERISCOPE group. Development and validation of a score to predict postoperative respiratory failure in a multicentre European cohort: A prospective, observational study. Eur J Anaesthesiol 2015;32:458-70. doi:10.1097/ EJA.0000000000000223

8 Canet J, Gallart L, Gomar C, et al, ARISCAT Group. Prediction of postoperative pulmonary complications in a population-based surgical cohort. Anesthesiology 2010;113:1338-50. doi:10.1097/ ALN.0b013e3181fc6e0a

9 Khuri SF, Henderson WG, DePalma RG, Mosca C, Healey NA, Kumbhani DJ, Participants in the VA National Surgical Quality Improvement Program. Determinants of long-term survival after major surgery and the adverse effect of postoperative complications. Ann Surg 2005;242:326-41, discussion 341-3.

10 Fernandez-Bustamante A, Frendl G, Sprung J, et al. Postoperative Pulmonary Complications, Early Mortality, and Hospital Stay Following Noncardiothoracic Surgery: A Multicenter Study by the Perioperative Research Network Investigators. JAMA Surg 2017;152:157-66. doi:10.1001/jamasurg.2016.4065

11 Miskovic A, Lumb AB. Postoperative pulmonary complications. Br J Anaesth 2017;118:317-34. doi:10.1093/bja/aex002

12 Sabaté S, Mazo V, Canet J. Predicting postoperative pulmonary complications: implications for outcomes and costs. Curr Opin Anaesthesiol 2014;27:201-9. doi:10.1097/ AC0.0000000000000045

13 Shander A, Fleisher LA, Barie PS, Bigatello LM, Sladen RN, Watson CB. Clinical and economic burden of postoperative pulmonary complications: patient safety summit on definition, risk-reducing interventions, and preventive strategies. Crit Care Med 2011;39:2163-72. doi:10.1097/CCM.0b013e31821f0522

14 Lawrence VA, Cornell JE, Smetana GW, American College of Physicians. Strategies to reduce postoperative pulmonary complications after noncardiothoracic surgery: systematic review for the American College of Physicians. Ann Intern Med 2006;144:596608. doi:10.7326/0003-4819-144-8-200604180-00011

15 Fleisher LA, Fleischmann KE, Auerbach AD, et al. 2014 ACC AHA guideline on perioperative cardiovascular evaluation and management of patients undergoing noncardiac surgery: executive summary: a report of the American College of Cardiology/American Heart Association Task Force on Practice Guidelines. Circulation 2014;130:2215-45. doi:10.1161/ CIR.0000000000000105

16 Moher D, Liberati A, Tetzlaff J, Altman DG, PRISMA Group. Preferred reporting items for systematic reviews and meta-analyses: the PRISMA statement. PLoS Med 2009;6:e1000097. doi:10.1371/ journal.pmed.1000097

17 Higgins JPT, Green S. Cochrane Handbook for Systematic Reviews of Interventions. Version 5.1.0. 2011. https://handbook-5-1.cochrane. org/.

18 Abbott TEF, Fowler AJ, Pelosi P, et al, StEP-COMPAC Group. A systematic review and consensus definitions for standardised end-points in perioperative medicine: pulmonary complications. $\mathrm{Br}$ 」 Anaesth 2018;120:1066-79. doi:10.1016/j.bja.2018.02.007

19 Higgins JP, Altman DG, Gøtzsche PC, et al, Cochrane Bias Methods Group, Cochrane Statistical Methods Group. The Cochrane Collaboration's tool for assessing risk of bias in randomised trials. BMJ 2011;343:d5928. doi:10.1136/bmj.d5928

20 Wan X, Wang W, Liu J, Tong T. Estimating the sample mean and standard deviation from the sample size, median, range and/ or interquartile range. BMC Med Res Methodol 2014;14:135 doi:10.1186/1471-2288-14-135 
21 Hozo SP, Djulbegovic B, Hozo I. Estimating the mean and variance from the median, range, and the size of a sample. BMC Med Res Methodol 2005;5:13. doi:10.1186/1471-2288-5-13

22 DerSimonian R, Laird N. Meta-analysis in clinical trials. Control Clin Trials 1986;7:177-88. doi:10.1016/0197-2456(86)90046-2

23 Jakobsen JC, Wetterslev J, Winkel P, Lange T, Gluud C. Thresholds for statistical and clinical significance in systematic reviews with meta-analytic methods. BMC Med Res Methodol 2014;14:120. doi:10.1186/1471-2288-14-120

24 Balshem $\mathrm{H}$, Helfand $\mathrm{M}$, Schünemann $\mathrm{HJ}$, et al. GRADE guidelines: 3. Rating the quality of evidence. J Clin Epidemiol 2011;64:401-6. doi:10.1016/j.jclinepi.2010.07.015

25 Wetterslev J, Thorlund K, Brok J, Gluud C. Trial sequential analysis may establish when firm evidence is reached in cumulative meta-analysis. J Clin Epidemiol 2008;61:64-75. doi:10.1016/j. jclinepi.2007.03.013

26 Thorlund K, Engstrøm J, Wetterslev J, et al. User manual for Trial Sequential Analysis (TSA). 2017. http://www.ctu.dk/tsa/files/ tsa_manual.pdf.

27 Gonenc M, Dural AC, Celik F, et al. Enhanced postoperative recovery pathways in emergency surgery: a randomised controlled clinical trial. Am / Surg 2014;207:807-14. doi:10.1016/j. amjsurg.2013.07.025

28 Futier E, Paugam-Burtz C, Godet T, et al, OPERA study investigators. Effect of early postextubation high-flow nasal cannula vs conventional oxygen therapy on hypoxaemia in patients after major abdominal surgery: a French multicentre randomised controlled trial (OPERA). Intensive Care Med 2016;42:1888-98. doi:10.1007/ s00134-016-4594-y

29 Hip Fracture Accelerated Surgical Treatment and Care Track (HIP ATTACK) Investigators. Accelerated care versus standard care among patients with hip fracture: the HIP ATTACK pilot trial. CMA/ 2014:186:E52-60. doi:10.1503/cmaj.130901

30 Jia Y, Jin G, Guo S, et al. Fast-track surgery decreases the incidence of postoperative delirium and other complications in elderly patients with colorectal carcinoma. Langenbecks Arch Surg 2014;399:77-84. doi:10.1007/s00423-013-1151-9

31 Feng F, Ji G, Li JP, et al. Fast-track surgery could improve postoperative recovery in radical total gastrectomy patients. World J Gastroenterol 2013;19:3642-8. doi:10.3748/wig.v19.i23.3642

32 Sokouti M, Aghdam BA, Golzari SEJ, Moghadaszadeh M. A comparative study of postoperative pulmonary complications using fast track regimen and conservative analgesic treatment: a randomized clinical trial. Tanaffos 2011;10:12-9.

33 Gao W, Liu DD, Li D, Cui GX. Effect of Therapeutic Hypercapnia on Inflammatory Responses to One-lung Ventilation in Lobectomy Patients. Anesthesiology 2015;122:1235-52. doi:10.1097/ ALN.0000000000000627

34 Refai M, Brunelli A, Xiumé F, et al. Short-term perioperative treatmen with ambroxol reduces pulmonary complications and hospital costs after pulmonary lobectomy: a randomized trial. Eur J Cardiothorac Surg 2009;35:469-73. doi:10.1016/j.ejcts.2008.11.015

35 Fegiz G. Prevention by ambroxol of bronchopulmonary complications after upper abdominal surgery: double-blind Italian multicenter clinical study versus placebo. Lung 1991;169:69-76. doi:10.1007/ BF02714144

36 Hewidy AA, Suliman LA, El Hefnawy E, et al. Immediate continuous positive airway pressure (CPAP) therapy after sleeve gastrectomy. Egypt J Chest Dis Tuberc 2016;65:701-610. doi:1016/j. ejcdt.2016.01.012

37 Barbagallo M, Ortu A, Spadini E, et al. Prophylactic use of helmet CPAP after pulmonary lobectomy: a prospective randomized controlled study. Respir Care 2012;57:1418-24. doi:10.4187/ respcare.00838

38 Böhner H, Kindgen-Milles D, Grust A, et al. Prophylactic nasal continuous positive airway pressure after major vascular surgery: results of a prospective randomized trial. Langenbecks Arch Surg 2002;387:21-6. doi:10.1007/s00423-002-0281-2

39 Denehy L, Carroll S, Ntoumenopoulos G, Jenkins S. A randomized controlled trial comparing periodic mask CPAP with physiotherapy after abdominal surgery. Physiother Res Int 2001;6:236-50. doi:10.1002/pri.231

40 Christensen EF, Schultz P, Jensen OV, et al. Postoperative pulmonary complications and lung function in high-risk patients: a comparison of three physiotherapy regimens after upper abdominal surgery in general anesthesia. Acta Anaesthesiol Scand 1991;35:97-104. doi:10.1111/j.1399-6576.1991.tb03255.x

41 Kindgen-Milles D, Müller E, Buhl R, et al. Nasal-continuous positive airway pressure reduces pulmonary morbidity and length of hospital stay following thoracoabdominal aortic surgery. Chest 2005;128:821-8. doi:10.1378/chest.128.2.821

42 Lorut C, Lefebvre A, Planquette B, et al. Early postoperative prophylactic noninvasive ventilation after major lung resection in COPD patients: a randomized controlled trial. Intensive Care Med 2014;40:220-7. doi:10.1007/s00134-013-3150-2
43 Perrin C, Jullien V, Vénissac N, et al. Prophylactic use of noninvasive ventilation in patients undergoing lung resectional surgery. Respir Med 2007:101:1572-8. doi:10.1016/j.rmed.2006.12.002

44 Nishimura M. High-flow nasal cannula oxygen therapy in adults. J Intensive Care 2015;3:15. doi:10.1186/s40560-015-0084-5

45 Yu Y, Qian X, Liu C, Zhu C. Effect of High-Flow Nasal Cannula versus Conventional Oxygen Therapy for Patients with Thoracoscopic Lobectomy after Extubation. Can Respir / 2017;2017:7894631. doi:10.1155/2017/7894631

46 Mazo V, Sabaté S, Canet I, et al. Prospective external validation of a predictive score for postoperative pulmonary complications. Anesthesiology 2014;121:219-31. doi:10.1097/ ALN.0000000000000334

47 Weingarten TN, Whalen FX, Warner DO, et al. Comparison of two ventilatory strategies in elderly patients undergoing major abdominal surgery. Br / Anaesth 2010;104:16-22. doi:10.1093/bja/aep319

48 Yang M, Ahn HJ, Kim K, et al. Does a protective ventilation strategy reduce the risk of pulmonary complications after lung cancer surgery?: a randomized controlled trial. Chest 2011;139:530-7. doi:10.1378/chest.09-2293

49 Severgnini P, Selmo G, Lanza C, et al. Protective mechanical ventilation during general anesthesia for open abdominal surgery improves postoperative pulmonary function. Anesthesiology 2013;118:1307-21. doi:10.1097/ ALN.0b013e31829102de

50 Futier E, Constantin J-M, Paugam-Burtz C, et al, IMPROVE Study Group. A trial of intraoperative low-tidal-volume ventilation in abdominal surgery. N Engl J Med 2013;369:428-37. doi:10.1056/ NEJMoa1301082

51 Hemmes SN, Gama de Abreu M, Pelosi P, Schultz MJ, PROVE Network Investigators for the Clinical Trial Network of the European Society of Anaesthesiology. High versus low positive end-expiratory pressure during general anaesthesia for open abdominal surgery (PROVHILO trial): a multicentre randomised controlled trial. Lancet 2014;384:495-503. doi:10.1016/S0140-6736(14)60416 5

52 Choi ES, Oh AY, In CB, Ryu JH, Jeon YT, Kim HG. Effects of recruitment manoeuvre on perioperative pulmonary complications in patients undergoing robotic assisted radical prostatectomy: A randomised single-blinded trial. PLoS One 2017;12:e0183311. doi:10.1371/ journal.pone.0183311

53 Aretha D, Fligou F, Kiekkas P, et al. Safety and effectiveness of alveolar recruitment maneuvers and positive end-expiratory pressure during general anesthesia for cesarean section: a prospective, randomized trial. Int J Obstet Anesth 2017;30:30-8. doi:10.1016/j. ijoa.2016.12.004

54 Treschan TA, Schaefer M, Kemper J, et al, PROVE Network Investigators. Ventilation with high versus low peep levels during general anaesthesia for open abdominal surgery does not affect postoperative spirometry: A randomised clinical trial. Eur J Anaesthesiol 2017;34:534-43. doi:10.1097/ EJA.0000000000000626

55 Park SJ, Kim BG, Oh AH, Han SH, Han HS, Ryu JH. Effects of intraoperative protective lung ventilation on postoperative pulmonary complications in patients with laparoscopic surgery: prospective, randomized and controlled trial. Surg Endosc 2016;30:4598-606. doi:10.1007/s00464-016-4797-x

56 Treschan TA, Kaisers W, Schaefer MS, et al. Ventilation with low tidal volumes during upper abdominal surgery does not improve postoperative lung function. Br / Anaesth 2012:109:263-71. doi:10.1093/bja/aes140

57 Qutub H, El-Tahan MR, Mowafi HA, El Ghoneimy YF, Regal MA, Al Saflan AA. Effect of tidal volume on extravascular lung water content during one-lung ventilation for video-assisted thoracoscopic surgery: a randomised, controlled trial. Eur J Anaesthesiol 2014;31:466-73. doi:10.1097/EJA.0000000000000072

58 Shen Y, Zhong M, Wu W, et al. The impact of tidal volume on pulmonary complications following minimally invasive esophagectomy: a randomized and controlled study[Erratum appears in J Thorac Cardiovasc Surg 2014:147:5441. I Thorac Cardiovasc Surg 2013;146:1267-73, discussion 1273-4. doi:10.1016/j. jtcvs.2013.06.043

59 Remístico PPI, Araúio S, de Figueiredo LC et al. Impact of alveolar recruitment maneuver in the postoperative period of videolaparoscopic bariatric surgery. Rev Bras Anestesiol 2011;61:163-8, 169-76, 88-94. doi:10.1016/S00347094(11)70021-6

60 Talab HF, Zabani IA, Abdelrahman HS, et al. Intraoperative ventilatory strategies for prevention of pulmonary atelectasis in obese patients undergoing laparoscopic bariatric surgery. Anesth Analg 2009;109:1511-6. doi:10.1213/ANE.0b013e3181ba7945

61 Lucangelo U, Antonaglia V, Zin WA, et al. High-frequency percussive ventilation improves perioperatively clinical evolution in pulmonary resection. Crit Care Med 2009;37:1663-9. doi:10.1097/ cCM.0b013e31819ef9e1 
62 Cai H, Gong H, Zhang L, Wang Y, Tian Y. Effect of low tidal volume ventilation on atelectasis in patients during general anesthesia: a computed tomographic scan. / Clin Anesth 2007;19:125-9. doi:10.1016/j.jclinane.2006.08.008

63 Choi G, Wolthuis EK, Bresser P, et al. Mechanical ventilation with lower tidal volumes and positive end-expiratory pressure prevents alveolar coagulation in patients without lung injury. Anesthesiology 2006;105:689-95. doi:10.1097/00000542-200610000-00013

64 Wetterslev J, Hansen EG, Roikjaer O, Kanstrup IL, Heslet L. Optimizing peroperative compliance with PEEP during upper abdominal surgery: effects on perioperative oxygenation and complications in patients without preoperative cardiopulmonary dysfunction. Eur J Anaesthesiol 2001;18:358-65. doi:10.1097/00003643200106000-00003

65 Chumillas S, Ponce JL, Delgado F, Viciano V, Mateu M. Prevention of postoperative pulmonary complications through respiratory rehabilitation: a controlled clinical study. Arch Phys Med Rehabil 1998;79:5-9. doi:10.1016/S0003-9993(98)90198-8

66 Condie F, Hack K Ross A et al. An investigation of the value of routine provision of post-operative chest physiotherapy in non-smoking patients undergoing elective abdominal surgery. Physiotherapy 1993;79:547-52. doi:10.1016/S0031 9406(10)60295-7

67 Dronkers J, Veldman A, Hoberg E, van der Waal C, van Meeteren N. Prevention of pulmonary complications after upper abdominal surgery by preoperative intensive inspiratory muscle training: a randomized controlled pilot study. Clin Rehabil 2008;22:134-42. doi:10.1177/0269215507081574

68 Fagevik Olsén M, Hahn I, Nordgren S, Lönroth H, Lundholm K. Randomized controlled trial of prophylactic chest physiotherapy in major abdominal surgery. Br J Surg 1997;84:1535-8. doi:10.1111/ j.1365-2168.1997.02828.x

69 Fagevik Olsén M, Josefson K, Lönroth H. Chest physiotherapy does not improve the outcome in laparoscopic fundoplication and verticalbanded gastroplasty. Surg Endosc 1999;13:260-3. doi:10.1007/ s004649900958

70 Kulkarni SR, Fletcher E, McConnell AK, Poskitt KR, Whyman MR. Pre-operative inspiratory muscle training preserves postoperative inspiratory muscle strength following major abdominal surgery - a randomised pilot study. Ann R Coll Surg Engl 2010;92:700-7. doi:10 .1308/003588410X12771863936648

71 Ludwig C, Angenendt S, Martins R, Mayer V, Stoelben E. Intermittent positive-pressure breathing after lung surgery. Asian Cardiovasc Thorac Ann 2011;19:10-3. doi:10.1177/0218492310394664

72 Mackay MR, Ellis E, Johnston C. Randomised clinical trial of physiotherapy after open abdominal surgery in high risk patients. Aust J Physiother 2005;51:151-9. doi:10.1016/S00049514(05)70021-0

73 Reeve JC, Nicol K, Stiller K et al. Does physiotherapy reduce the incidence of postoperative pulmonary complications following pulmonary resection via open thoracotomy? A preliminary randomised single-blind clinical trial. Eur / Cardiothorac Surg 2010;37:1158-66. doi:10.1016/j.ejcts.2009.12.011

74 Silva YR, Li SK, Rickard MJFX. Does the addition of deep breathing exercises to physiotherapy-directed early mobilisation alter patient outcomes following high-risk open upper abdominal surgery? Cluster randomised controlled trial. Physiotherapy 2013;99:187-93. doi:10.1016/j.physio.2012.09.006

75 van Adrichem EJ, Meulenbroek RL, Plukker JTM, Groen H, van Weert E. Comparison of two preoperative inspiratory muscle training programs to prevent pulmonary complications in patients undergoing esophagectomy: a randomized controlled pilot study. Ann Surg Oncol 2014:21:2353-60 doi:10.1245/s10434-014-3612-y

76 Brocki BC, Andreasen JJ, Langer D, Souza DS, Westerdahl E. Postoperative inspiratory muscle training in addition to breathing exercises and early mobilization improves oxygenation in high-risk patients after lung cancer surgery: a randomized controlled trial. Eur J Cardiothorac Surg 2016;49:1483-91. doi:10.1093/ejcts/ezv359

77 Mann C, Pouzeratte Y, Boccara G, et al. Comparison of intravenous or epidural patient-controlled analgesia in the elderly after major abdominal surgery. Anesthesiology 2000;92:433-41. doi:10.1097/00000542-200002000-00025

78 Norris El, Beattie C, Perler BA, et al. Double-masked randomized trial comparing alternate combinations of intraoperative anesthesia and postoperative analgesia in abdominal aortic surgery. Anesthesiology 2001;95:1054-67. doi:10.1097/00000542 200111000-00006

79 Park WY, Thompson JS, Lee KK. Effect of epidural anesthesia and analgesia on perioperative outcome: a randomized, controlled Veterans Affairs cooperative study. Ann Surg 2001;234:560-9, discussion 569-71. doi:10.1097/00000658-200110000-00015

80 Radovanović D, Radovanović Z, Škorić-Jokić S, Tatić M, Mandić A, Ivković-Kapicl T. Thoracic Epidural Versus Intravenous PatientControlled Analgesia after Open Colorectal Cancer Surgery. Acta Clin Croat 2017;56:244-54. doi:10.20471/acc.2017.56.02.07
81 Rigg JR, Jamrozik K, Myles PS, et al, MASTER Anaethesia Tria Study Group. Epidural anaesthesia and analgesia and outcome of major surgery: a randomised trial. Lancet 2002;359:1276-82. doi:10.1016/S0140-6736(02)08266-1

82 Zhu Z, Wang C, Xu C, Cai Q. Influence of patient-controlled epidural analgesia versus patient-controlled intravenous analgesia on postoperative pain control and recovery after gastrectomy for gastric cancer: a prospective randomized trial. Gastric Cancer 2013;16:193200. doi:10.1007/s10120-012-0168-z

83 Boisseau N, Rabary O, Padovani B, et al. Improvement of 'dynamic analgesia' does not decrease atelectasis after thoracotomy. $\mathrm{Br}$ J Anaesth 2001;87:564-9. doi:10.1093/bja/87.4.564

84 Garnett RL, MacIntyre A, Lindsay P, et al. Perioperative ischaemia in aortic surgery: combined epidural/general anaesthesia and epidural analgesia vs general anaesthesia and i.v. analgesia. Can J Anaesth 1996:43:769-77. doi:10.1007/BF03013027

85 Davies MJ, Silbert BS, Mooney PJ, Dysart RH, Meads AC Combined epidural and general anaesthesia versus general anaesthesia for abdominal aortic surgery: a prospective randomised trial. Anaesth Intensive Care 1993;21:790-4 doi:10.1177/0310057X9302100607

86 Kilbride MJ, Senagore AJ, Mazier WP, Ferguson C, Ufkes T. Epidural analgesia. Surg Gynecol Obstet 1992:174:137-40.

87 Tuman KJ, McCarthy RJ, March RJ, DeLaria GA, Patel RV, Ivankovich AD. Effects of epidural anesthesia and analgesia on coagulation and outcome after major vascular surgery. Anesth Analg 1991;73:696704. doi:10.1213/00000539-199112000-00005

88 Boyd O, Grounds RM, Bennett ED. A randomized clinical trial of the effect of deliberate perioperative increase of oxygen delivery on mortality in high-risk surgical patients. JAMA 1993;270:2699-707. doi:10.1001/jama.1993.03510220055034

89 Wilson J, Woods I, Fawcett J, et al. Reducing the risk of major elective surgery: randomised controlled trial of preoperative optimisation of oxygen delivery. BMJ 1999;318:1099-103. doi:10.1136/ bmj.318.7191.1099

90 Valentine RJ, Duke ML, Inman MH, et al. Effectiveness of pulmonary artery catheters in aortic surgery: a randomized trial. J Vasc Surg 1998;27:203-11, discussion 211-2. doi:10.1016/S0741 5214(98)70351-9

91 Gan TJ, Soppitt A, Maroof M, et al. Goal-directed intraoperative fluid administration reduces length of hospital stay after major surgery. Anesthesiology 2002;97:820-6. doi:10.1097/00000542200210000-00012

92 Venn R, Steele A, Richardson P, Poloniecki J, Grounds M, Newman P. Randomized controlled trial to investigate influence of the fluid challenge on duration of hospital stay and perioperative morbidity in patients with hip fractures. Br J Anaesth 2002;88:65-71. doi:10.1093/bja/88.1.65

93 Sandham JD, Hull RD, Brant RF, et al, Canadian Critical Care Clinical Trials Group. A randomized, controlled trial of the use of pulmonary-artery catheters in high-risk surgical patients. N Engl J Med 2003;348:5-14. doi:10.1056/NEJMoa021108

94 Pearse R, Dawson D, Fawcett J, Rhodes A, Grounds RM, Bennett ED. Early goal-directed therapy after major surgery reduces complications and duration of hospital stay. A randomised, controlled trial [ISRCTN38797445][ISRCTN38797445]. Crit Care 2005:9:R687-93. doi:10.1186/cc3887

95 Pearse RM, Harrison DA, MacDonald N, et al, OPTIMISE Study Group. Effect of a perioperative, cardiac output-guided hemodynamic therapy algorithm on outcomes following major gastrointestinal surgery: a randomized clinical trial and systematic review. JAMA 2014;311:2181-90. doi:10.1001/jama.2014.5305

96 Lopes MR, Oliveira MA, Pereira VO, Lemos IP, Auler JOJr, Michard F. Goal-directed fluid management based on pulse pressure variation monitoring during high-risk surgery: a pilot randomized controlled trial. Crit Care 2007;11:R100. doi:10.1186/cc6117

97 Benes J, Chytra I, Altmann P, et al. Intraoperative fluid optimization using stroke volume variation in high risk surgical patients: results of prospective randomized study. Crit Care 2010;14:R118. doi:10.1186/cc9070

98 Mayer J, Boldt J, Mengistu AM, Röhm KD, Suttner S. Goal-directed intraoperative therapy based on autocalibrated arterial pressure waveform analysis reduces hospital stay in high-risk surgical patients: a randomized, controlled trial. Crit Care 2010;14:R18. doi:10.1186/ cc8875

99 Wenkui Y, Ning L, Jianfeng G, et al. Restricted peri-operative fluid administration adjusted by serum lactate level improved outcome after major elective surgery for gastrointestinal malignancy. Surgery 2010;147:542-52. doi:10.1016/j.surg.2009.10.036

100 Cecconi M, Fasano N, Langiano N, et al. Goal-directed haemodynamic therapy during elective total hip arthroplasty under regional anaesthesia. Crit Care 2011;15:R132. doi:10.1186/cc10246

101 Ackland GL, Iqbal S, Paredes LG, et al, POM-O (PostOperative Morbidity-Oxygen delivery) study group. Individualised oxygen delivery targeted haemodynamic therapy in high-risk surgical 
patients: a multicentre, randomised, double-blind, controlled, mechanistic trial. Lancet Respir Med 2015;3:33-41. doi:10.1016/ S2213-2600(14)70205-X

102 Lobo DN, Bostock KA, Neal KR, Perkins AC, Rowlands BJ, Allison SP. Effect of salt and water balance on recovery of gastrointestinal function after elective colonic resection: a randomised controlled trial. Lancet 2002;359:1812-8. doi:10.1016/S01406736(02)08711-1

103 Brandstrup B, Tønnesen H, Beier-Holgersen R, et al, Danish Study Group on Perioperative Fluid Therapy. Effects of intravenous fluid restriction on postoperative complications: comparison of two perioperative fluid regimens: a randomized assessor-blinded multicenter trial. Ann Surg 2003;238:641-8. doi:10.1097/01. sla.0000094387.50865.23

104 Muller S, Zalunardo MP, Hubner M, Clavien PA, Demartines N, Zurich Fast Track Study Group. A fast-track program reduces complications and length of hospital stay after open colonic surgery. Gastroenterology 2009;136:842-7. doi:10.1053/j. gastro.2008.10.030

105 Nisanevich V, Felsenstein I, Almogy G, Weissman C, Einav S, Matot I. Effect of intraoperative fluid management on outcome after intraabdominal surgery. Anesthesiology 2005;103:25-32 doi:10.1097/00000542-200507000-00008

106 Holte K, Foss NB, Andersen J, et al. Liberal or restrictive fluid administration in fast-track colonic surgery: a randomized, doubleblind study. Br I Anaesth 2007:99:500-8. doi:10.1093/bja/aem21

107 Holte K, Kristensen BB, Valentiner L, Foss NB, Husted H, Kehlet H. Liberal versus restrictive fluid management in knee arthroplasty: a randomized, double-blind study. Anesth Analg 2007;105:465-74 doi:10.1213/01 ane 0000263268.08222 .19

108 McArdle GT, McAuley DF, McKinley A, Blair P, Hoper M, Harkin DW. Preliminary results of a prospective randomized trial of restrictive versus standard fluid regime in elective open abdominal aortic aneurysm repair. Ann Surg 2009;250:28-34. doi:10.1097/ SLA.ob013e3181ad61c8

109 Futier $\mathrm{E}$, Constantin IM, Petit A, et al. Conservative vs restrictive individualized goal-directed fluid replacement strategy in major abdominal surgery: A prospective randomized trial. Arch Surg 2010;145:1193-200. doi:10.1001/archsurg.2010.275

110 Abraham-Nordling M, Hjern F, Pollack J, Prytz M, Borg T, Kressner U. Randomized clinical trial of fluid restriction in colorectal surgery. $\mathrm{Br}$. Surg 2012;99:186-91. doi:10.1002/bjs.7702

111 de la Gala F, Piñeiro P, Reyes A, et al. Postoperative pulmonary complications, pulmonary and systemic inflammatory responses after lung resection surgery with prolonged one-lung ventilation. Randomized controlled trial comparing intravenous and inhalational anaesthesia. Br J Anaesth 2017;119:655-63. doi:10.1093/bja/ aex230

112 Parker MJ, Griffiths R. General versus regional anaesthesia for hip fractures. A pilot randomised controlled trial of 322 patients. Injury 2015;46:1562-6. doi:10.1016/j.injury.2015.05.004

113 Berg H, Roed J, Viby-Mogensen J, et al. Residual neuromuscular block is a risk factor for postoperative pulmonary complications. A prospective, randomised, and blinded study of postoperative pulmonary complications after atracurium, vecuronium and pancuronium. Acta Anaesthesiol Scand 1997;41:1095-103. doi:10.1111/j.1399-6576.1997.tb04851.x

114 Brueckmann B, Sasaki N, Grobara P, et al. Effects of sugammadex on incidence of postoperative residual neuromuscular blockade: a randomized, controlled study. Br J Anaesth 2015;115:743-51. doi:10.1093/bja/aev104

115 Wong PF, Kumar S, Bohra A, Whetter D, Leaper DJ. Randomized clinical trial of perioperative systemic warming in major elective abdominal surgery. Br J Surg 2007;94:421-6. doi:10.1002/bjs.5631

116 Monsel A, Lu Q, Le Corre M, et al, TETRIS Study Group. Tapered-cuff Endotracheal Tube Does Not Prevent Early Postoperative Pneumonia Compared with Spherical-cuff Endotracheal Tube after Major Vascular Surgery: A Randomized Controlled Trial. Anesthesiology 2016;124:1041-52 doi:10.1097/ALN.0000000000001053

117 Tyagi A, Agrawal D, Gupta S, et al. Role of breathing system filter in prevention of postoperative nosocomial respiratory infection: A pilot study. J Anaesthesiol Clin Pharmacol 2010;26:345-9.

118 Lai C-J, Liu C-M, Wu C-Y, Tsai FF, Tseng PH, Fan SZ. I-Gel is a suitable alternative to endotracheal tubes in the laparoscopic pneumoperitoneum and trendelenburg position. BMC Anesthesiol 2017;17:3. doi:10.1186/s12871-016-0291-1

119 Gaitini LA, Vaida SJ, Somri M, Yanovski B, Ben-David B, Hagberg CA. A randomized controlled trial comparing the ProSeal Laryngea Mask Airway with the Laryngeal Tube Suction in mechanically ventilated patients. Anesthesiology 2004:101:316-20. doi:10.1097/00000542-200408000-00011

120 Esme H, Apiliogullari B, Duran FM, Yoldas B, Bekci TT. Comparison between intermittent intravenous analgesia and intermittent paravertebral subpleural analgesia for pain relief after thoracotomy. Eur J Cardiothorac Surg 2012;41:10-3.
121 Şen M, Özol D, Bozer M. Influence of preemptive analgesia on pulmonary function and complications for laparoscopic cholecystectomy. Dig Dis Sci 2009;54:2742-7. doi:10.1007/ s10620-008-0677-0

122 Fléron M-H, Weiskopf RB, Bertrand M, et al. A comparison of intrathecal opioid and intravenous analgesia for the incidence of cardiovascular, respiratory, and renal complications after abdominal aortic surgery. Anesth Analg 2003;97:2-12. doi:10.1213/01. ANE.0000066355.07482.0C

123 Lee SH, Lee CY, Lee JG, Kim N, Lee HM, Oh YJ. Intraoperative Dexmedetomidine Improves the Quality of Recovery and Postoperative Pulmonary Function in Patients Undergoing Video-assisted Thoracoscopic Surgery: A CONSORT-Prospective, Randomized, Controlled Trial. Medicine (Baltimore) 2016;95:e2854 doi:10.1097/MD.0000000000002854

124 Fisher BW, Majumdar SR, McAlister FA. Predicting pulmonary complications after nonthoracic surgery: a systematic review of blinded studies. Am J Med 2002;112:219-25. doi:10.1016/S0002 9343(01)01082-8

125 Khan NA, Quan H, Bugar JM, Lemaire JB, Brant R, Ghali WA. Association of postoperative complications with hospital costs and length of stay in a tertiary care center. J Gen Intern Med 2006:21:177-80. doi:10.1007/s11606-006-0254-1

126 Neto AS, Hemmes SN, Barbas CS, et al, PROVE Network Investigators. Association between driving pressure and development of postoperative pulmonary complications in patients undergoing mechanical ventilation for general anaesthesia: a meta-analysis of individual patient data. Lancet Respir Med 2016;4:272-80. doi:10.1016/S2213-2600(16)00057-6

127 Yang D, Grant MC, Stone A, Wu CL, Wick EC. A Meta-analysis of Intraoperative Ventilation Strategies to Prevent Pulmonary Complications: Is Low Tidal Volume Alone Sufficient to Protect Healthy Lungs?Ann Surg 2016;263:881-7. doi:10.1097| SLA.0000000000001443

128 Guay J, Ochroch EA. Intraoperative use of low volume ventilation to decrease postoperative mortality, mechanical ventilation, lengths of stay and lung injury in patients without acute lung injury. Cochrane Database Syst Rev 2015;(12):CD011151. doi:10.1002/14651858. CD011151.pub2

129 Tao T, Bo L, Chen F, et al. Effect of protective ventilation on postoperative pulmonary complications in patients undergoing general anaesthesia: a meta-analysis of randomised controlled trials. BMJ Open 2014:4:e05208 doi:10.1136/bmiopen-2014-005208

130 Serpa Neto A, Hemmes SN, Barbas CS, et al, PROVE Network Investigators. Protective versus Conventional Ventilation for Surgery: A Systematic Review and Individual Patient Data Meta-analysis. Anesthesiology 2015;123:66-78. doi:10.1097/ ALN.0000000000000706

131 Nielsen J, Østergaard M, Kjaergaard J, et al. Lung recruitment maneuver depresses central hemodynamics in patients following cardiac surgery. Intensive Care Med 2005;31:1189-94 doi:10.1007/s00134-005-2732-z

132 Ferrando C, Suarez-Sipmann F, Tusman G, et al. Open lung approach versus standard protective strategies: Effects on driving pressure and ventilatory efficiency during anesthesia - A pilot, randomized controlled trial. PLoS One 2017;12:e0177399. doi:10.1371/journal. pone.0177399

133 Ferrando C, Soro M, Unzueta C, et al, Individualized PeRioperative Open-lung VEntilation (iPROVE) Network. Individualised perioperative open-lung approach versus standard protective ventilation in abdominal surgery (iPROVE): a randomised controlled trial. Lancet Respir Med 2018;6:193-203. doi:10.1016/S22132600(18)30024-9

134 Patel JM, Baker R, Yeung J, Small C, West Midlands-Trainee Research and Audit Network (WM-TRAIN). Intra-operative adherence to lungprotective ventilation: a prospective observational study. Perioper Med (Lond) 2016;5:8. doi:10.1186/s13741-016-0033-4

135 Levin MA, McCormick PJ, Lin HM, Hosseinian L, Fischer GW. Low intraoperative tidal volume ventilation with minimal PEEP is associated with increased mortality. Br J Anaesth 2014;113:97-108 doi:10.1093/bja/aeu054

136 Watson X, Chereshneva M, Odor PM, Chis Ster I, Cecconi M, Pan-London Perioperative Audit and Research Network (PLAN). Adoption of Lung Protective ventilation IN patients undergoing Emergency laparotomy: the ALPINE study. A prospective multicentre observational study. Br J Anaesth 2018;121:909-17. doi:10.1016/j. bja.2018.04.048

137 Myles PS, Bellomo R, Corcoran T, et al, Australian and New Zealand College of Anaesthetists Clinical Trials Network and the Australian and New Zealand Intensive Care Society Clinical Trials Group. Restrictive versus Liberal Fluid Therapy for Major Abdominal Surgery. N Engl I Med 2018;378:2263-74. doi:10.1056/NEJMoa1801601

138 Calvo-Vecino IM, Ripollés-Melchor J, Mythen MG, et al, FEDORA Trial Investigators Group. Effect of goal-directed haemodynamic therapy on postoperative complications in low-moderate risk surgical 
patients: a multicentre randomised controlled trial (FEDORA trial). $\mathrm{Br}$ J Anaesth 2018;120:734-44. doi:10.1016/j.bja.2017.12.018

139 Edwards MR, Forbes G, MacDonald N, et al, OPTIMISE II investigators. Optimisation of Perioperative Cardiovascular Management to Improve Surgical Outcome II (OPTIMISE II) trial: study protocol for a multicentre international trial of cardiac output-guided fluid therapy with low-dose inotrope infusion compared with usual care in patients undergoing major elective gastrointestinal surgery. BMf Open 2019:9:e023455. doi:10.1136/bmjopen-2018-023455

140 Gilhooly D, Green SA, McCann C, Black N, Moonesinghe SR. Barriers and facilitators to the successful development, implementation and evaluation of care bundles in acute care in hospital: a scoping review. Implement Sci 2019;14:47. doi:10.1186/s13012-019-0894-2

141 Chopra V, Shojania KG. Recipes for checklists and bundles: one part active ingredient, two parts measurement. BMJ Qual Saf 2013;22:93-6. doi:10.1136/bmjas-2012-001480

142 Schwulst SJ, Mazuski JE. Surgical prophylaxis and other complication avoidance care bundles. Surg Clin North Am 2012;92:285-305, ix. doi:10.1016/j.suc.2012.01.011

143 Munday GS, Deveaux P, Roberts H, Fry DE, Polk HC. Impact of implementation of the Surgical Care Improvement Project and future strategies for improving quality in surgery. Am / Surg 2014;208:83540. doi:10.1016/i.amjsurg.2014.05.005

144 Tablan OC, Anderson LJ, Besser R, Bridges C, Hajjeh R, CDC, Healthcare Infection Control Practices Advisory Committee. Guidelines for preventing health-care--associated pneumonia, 2003: recommendations of CDC and the Healthcare Infection Control Practices Advisory Committee. MMWR Recomm Rep 2004;53(RR3):1-36.

145 American Thoracic Society, Infectious Diseases Society of America. Guidelines for the management of adults with hospital-acquired, ventilator-associated, and healthcare-associated pneumonia. Am I Respir Crit Care Med 2005;171:388-416. doi:10.1164/ rccm.200405-644ST

146 Cassidy MR, Rosenkranz P, McCabe K, Rosen JE, McAneny D. I COUGH: reducing postoperative pulmonary complications with a multidisciplinary patient care program. JAMA Surg 2013;148:740-5. doi:10.1001/jamasurg.2013.358

147 Griffiths SV, Conway DH, Sander M, Jammer I, Grocott MPW, Creagh-Brown BC, POPC-CB Investigators. What are the optimum components in a care bundle aimed at reducing post-operative pulmonary complications in high-risk patients?Perioper Med (Lond) 2018;7:7. doi:10.1186/s13741-018-0084-9

148 Moore JA, Conway DH, Thomas N, Cummings D, Atkinson D. Impact of a peri-operative quality improvement programme on postoperative pulmonary complications. Anaesthesia 2017;72:317-27. doi:10.1111/anae.13763

149 Meyer MJ, Bateman BT, Kurth T, Eikermann M. Neostigmine reversal doesn't improve postoperative respiratory safety. BMJ 2013;346:f1460. doi:10.1136/bmj.f1460

150 McLean DJ, Diaz-Gil D, Farhan HN, Ladha KS, Kurth T, Eikermann M. Dose-dependent Association between Intermediate-acting Neuromuscular-blocking Agents and Postoperative Respiratory Complications. Anesthesiology 2015;122:1201-13. doi:10.1097/ ALN.0000000000000674

151 Kirmeier E, Eriksson LI, Lewald H, et al, POPULAR Contributors. Post-anaesthesia pulmonary complications after use of muscle relaxants (POPULAR): a multicentre, prospective observational study. Lancet Respir Med 2019;7:129-40. doi:10.1016/S22132600(18)30294-7

152 Butterly A, Bittner EA, George E, Sandberg WS, Eikermann M, Schmidt $U$. Postoperative residual curarization from intermediate-acting neuromuscular blocking agents delays recovery room discharge. $\mathrm{Br}$ J Anaesth 2010:105:304-9. doi:10.1093/bja/aeq157

153 Grabitz SD, Rajaratnam N, Chhagani K, et al. The Effects of Postoperative Residual Neuromuscular Blockade on Hospital Costs and Intensive Care Unit Admission: A Population-Based Cohort Study. Anesth Analg 2019;128:1129-36. doi:10.1213/ ANE.0000000000004028

154 Pearse RM, Abbott TE, Haslop R, et al. The Prevention of Respiratory Insufficiency after Surgical Management (PRISM) Trial. Report of the protocol for a pragmatic randomized controlled trial of CPAP to prevent respiratory complications and improve survival following major abdominal surgery Minerva Anestesiol 2017:83:175-82.

155 National Institute for Health Research. Effectiveness and costeffectiveness of INSPIRatory musclE training (IMT) for reducing postoperative pulmonary complications (PPC): a sham-controlled randomised controlled trial (RCT) (INSPIRE). 2019. https:// fundingawards.nihr.ac.uk/award/16/140/07

\section{Appendix 1-4}

